\title{
Food sources of fructose-containing sugars and glycaemic control: systematic review and meta-analysis of controlled intervention studies
}

\author{
Vivian L Choo, ${ }^{1,2,3}$ Effie Viguiliouk, ${ }^{1,2}$ Sonia Blanco Mejia, ${ }^{1,2}$ Adrian I Cozma, ${ }^{1,2,4}$ \\ Tauseef A Khan, ${ }^{1,2}$ Vanessa Ha, ${ }^{1,5,6}$ Thomas M S Wolever, ${ }^{1,2,7,8}$ Lawrence A Leiter, 1,2,7,8 \\ Vladimir Vuksan, ${ }^{1,2,7,8}$ Cyril W C Kendall, ${ }^{1,2,9}$ Russell J de Souza, ${ }^{1,2,6}$ David J A Jenkins, 1,2,7,8 \\ John L Sievenpiper ${ }^{1,2,7,8}$
}

For numbered affiliations see end of article.

Correspondence to:

J L Sievenpiper john.

sievenpiper@utoronto.ca

Additional material is published online only. To view please visit the journal online.

Cite this as: BMJ 2018;363:k4644 http://dx.doi.org/10.1136/bmi.k4644

Accepted: 28 October 2018

\section{ABSTRACT}

OBJECTIVE

To assess the effect of different food sources of fructose-containing sugars on glycaemic control at different levels of energy control.

\section{DESIGN}

Systematic review and meta-analysis of controlled intervention studies.

\section{DATA SOURCES}

Medine, Embase, and the Cochrane Library up to 25 April 2018.

\section{ELIGIBILITY CRITERIA FOR SELECTING STUDIES} Controlled intervention studies of at least seven days' duration and assessing the effect of different food sources of fructose-containing sugars on glycaemic control in people with and without diabetes were included. Four study designs were prespecified on the basis of energy control: substitution studies (sugars in energy matched comparisons with other macronutrients), addition studies (excess energy from sugars added to diets), subtraction studies (energy from sugars subtracted from diets), and ad libitum studies (sugars freely replaced by other macronutrients without control for energy). Outcomes

\section{WHAT IS ALREADY KNOWN ON THIS TOPIC}

Current dietary guidelines recommend a reduction to less than $5-10 \%$ energy in free sugars, especially fructose-containing sugars from sugars-sweetened beverages (SSBs)

In the published literature, fructose-containing sugars from SSBs have shown an adverse association with diabetes incidence, and free fructose adding excess energy to diets has shown a harmful effect on glycaemic control

As dietary guidelines shift from a focus on single nutrients to a focus on dietary patterns, it is unclear whether the evidence for SSBs and excess energy from fructose holds for other important food sources of fructose-containing sugars at different levels of energy control

\section{WHAT THIS STUDY ADDS}

This systematic review and meta-analysis of 155 controlled intervention studies suggests that most food sources of fructose-containing sugars do not have a harmful effect on glycaemic control in energy matched substitutions for other macronutrients

However, several food sources do have harmful effects when adding excess energy to the diet, especially SSBs

Until more information is available, public health professionals should be aware that harmful effects of fructose-containing sugars on glycaemic control seem to be mediated by energy and food source

were glycated haemoglobin (HbA1c), fasting blood glucose, and fasting blood glucose insulin.

\section{DATA EXTRACTION AND SYNTHESIS}

Four independent reviewers extracted relevant data and assessed risk of bias. Data were pooled by random effects models and overall certainty of the evidence assessed by the GRADE approach (grading of recommendations assessment, development, and evaluation).

\section{RESULTS}

155 study comparisons $(n=5086)$ were included. Total fructose-containing sugars had no harmful effect on any outcome in substitution or subtraction studies, with a decrease seen in $\mathrm{HbA} 1 \mathrm{c}$ in substitution studies (mean difference $-0.22 \%$ (95\% confidence interval to $-0.35 \%$ to $-0.08 \%),-25.9 \mathrm{mmol} / \mathrm{mol}(-27.3$ to -24.4)), but a harmful effect was seen on fasting insulin in addition studies $(4.68 \mathrm{pmol} / \mathrm{L}(1.40$ to 7.96)) and ad libitum studies (7.24 pmol/L (0.47 to 14.00)). There was interaction by food source, with specific food sources showing beneficial effects (fruit and fruit juice) or harmful effects (sweetened milk and mixed sources) in substitution studies and harmful effects (sugars-sweetened beverages and fruit juice) in addition studies on at least one outcome. Most of the evidence was low quality.

\section{CONCLUSIONS}

Energy control and food source appear to mediate the effect of fructose-containing sugars on glycaemic control. Although most food sources of these sugars (especially fruit) do not have a harmful effect in energy matched substitutions with other macronutrients, several food sources of fructosecontaining sugars (especially sugars-sweetened beverages) adding excess energy to diets have harmful effects. However, certainty in these estimates is low, and more high quality randomised controlled trials are needed.

STUDY REGISTRATION

Clinicaltrials.gov (NCT02716870).

\section{Introduction}

The role of sugars in the development of cardiometabolic disease is actively debated. ${ }^{12}$ In particular, fructose has recently emerged as a serious public health concern, as ecological parallels have been drawn between the introduction of high fructose corn syrup (HFCS) as a popular sweetener during the 1970 s and global rises in obesity and diabetes prevalence. ${ }^{34}$ 
Despite early considerations for the use of fructose as an alternative sweetener in people with diabetes, owing to its observed potential to lower postprandial glycaemic excursions when compared with isocaloric amounts of starch, ${ }^{5}$ increasing evidence has suggested that fructose could be particularly detrimental to metabolic health, and even more so than other sugars. ${ }^{6}$ This view has received support from ecological evidence $^{4}$ as well as animal studies ${ }^{7-9}$ and select human intervention studies. ${ }^{10-12}$ However, higher levels of evidence from systematic reviews and meta-analyses of controlled human intervention studies have failed to show adverse glycaemic effects unique to fructose, and have even shown a beneficial effect on glycated blood proteins of fructose in isocaloric substitution for other carbohydrates in the diet in people with diabetes. ${ }^{13}$

Whether a causal link exists between fructose and the development of diabetes and related cardiometabolic comorbidities continues to be contested. But much less appreciated in this debate are the consumption patterns and levels at which fructose is normally consumed in the diet. Fructose is rarely consumed in isolation under real world conditions. ${ }^{14}$ It is present in various food sources containing comparable amounts of glucose, and the proportion of fructose co-ingested with glucose has been suggested to influence fructose metabolism. ${ }^{15}$ In its most commonly consumed form, sucrose (table sugar), fructose is part of a disaccharide with glucose in a 50:50 ratio. HFCS is also a glucosefructose mix, with varying fructose content (42-55\% molecular weight) in a free, unbound monosaccharide form. Similarly, less refined sources of fructosecontaining sugars-including honey, agave, and maple syrup-are composed of varying proportions of fructose and glucose, while natural sources of fructose present in various fruit and vegetables also co-exist with glucose. These fructose-containing sugars are found in the diet in a variety of food sources, ranging from "nutrient poor" sources of added sugars (such as sugars-sweetened beverages (SSBs)), to "nutrient dense" sources of bound sugars (such as fruit). Evidence from prospective cohorts on diabetes risk have shown different associations depending on the food source of the sugars (that is, positive associations with SSBs ${ }^{1617}$ and inverse association with fruit ${ }^{1819}$ ).

As dietary guidelines shift from nutrient based recommendations to more food and dietary pattern based recommendations, ${ }^{20} 21$ it is important to understand the role of the food matrix in modifying the effect of fructose-containing sugars. Current recommendations from the World Health Organization, United States, and United Kingdom have focused on the reduction of added or free sugars (added sugars plus sugars contained in fruit juices) to less than $5-10 \%$ energy, ${ }^{20} 22{ }^{23}$ especially free fructosecontaining sugars from SSBs. ${ }^{20}$ Whether the evidence for added or free sugars and SSBs can be generalised to all food sources of fructose-containing sugars in relation to their effects on surrogate markers of type 2 diabetes has not yet been determined. We conducted a systematic review and meta-analysis of controlled intervention studies to determine the effect of food sources of fructose-containing sugars at different levels of energy control on glycaemic control in people with and without diabetes.

\section{Methods}

This systematic review and meta-analysis was conducted according to the Cochrane Handbook for Systematic Reviews and Interventions, ${ }^{24}$ with all results reported according to the PRISMA (preferred reporting items for systematic reviews and metaanalyses) guidelines. ${ }^{25}$ The study protocol was registered at Clinicaltrials.gov (NCT02716870).

\section{Data sources}

Medline, Embase, and the Cochrane Central Register of Controlled Studies were searched up to 25 April 2018. We used the following search terms: fructose OR dietary sucrose, OR HFCS OR sugar OR sugar* sweetened beverage ${ }^{\star}$ OR honey AND glyc? em* OR insulin OR HbA1c OR fructosamine OR blood glucose OR gly^ albumin (supplementary table 1). Validated filters from the McMaster University Health Information Research Unit were applied to limit the database search to controlled studies only, ${ }^{26}$ and electronic searches were supplemented with manual searches of references from included studies.

\section{Study selection}

We included reports of controlled intervention studies lasting at least seven days and comparing the effect of diets of fructose-containing sugars (fructose, sucrose, HFCS, honey, syrups) from various food sources with control diets free of or lower in these sugars on outcome measures of glycaemic control (fasting glucose, fasting insulin, and glycated haemoglobin (HbA1c)) in people with and without diabetes. We excluded reports of studies of meal replacements and studies of interventions of rare sugars that contained fructose (eg, isomaltulose or melzitose) or were low calorie epimers of fructose (eg, allulose, tagatose, sorbose), and reports of studies that used these sugars as the comparator. Four study designs based on the control of energy were prespecified:

- Substitution studies, in which food sources of fructose-containing sugars were compared with food sources of other non-fructose-containing macronutrients under energy matched conditions (isocaloric comparison).

- Addition studies, in which excess energy from food sources of fructose-containing sugars was added to background diets compared with the same background diets alone without the excess energy from fructose-containing sugars, with or without the use of low calorie sweeteners to match sweetness (hypercaloric comparison).

- Subtraction studies, in which energy from food sources of fructose-containing sugars was subtracted from background diets through displacement by water or low calorie sweeteners, or by elimination 
of the food sources of fructose-containing sugars altogether compared with the original background diets (hypocaloric comparison).

- Ad libitum studies, in which food sources of fructosecontaining sugars were compared with food sources of other non-fructose-containing macronutrients without any strict control of either the study foods or the background diets, to allow for free replacement of the energy from fructose-containing sugars with the energy from other macronutrients (free-feeding comparison).

We included reports containing both randomised and non-randomised controlled intervention studies. An intervention study was considered non-randomised if the authors explicitly stated that a method of randomisation was not used or randomisation was not reported in the allocation of participants to the intervention or control treatments in parallel designs or the sequence of the treatments in crossover designs. In reports containing more than one study comparison, we included all available study comparisons.

\section{Data extraction}

Data from included reports were individually extracted at least twice by four separate reviewers. Relevant information included number of participants, setting, underlying disease status of participants, study design, level of feeding control, randomisation, comparator, fructose-containing sugars type, food sources of fructose-containing sugars, macronutrient profile of the diets, follow-up duration, energy balance, and funding sources. The three outcome variables were HbA1c, fasting blood glucose, and fasting blood insulin. HbA1c was reported instead of total glycated blood proteins as originally indicated in our protocol (identification number NCT02716870), because mean differences for these values were considered more clinically relevant and did not require the use of standardised mean differences needed to the different glycated blood proteins. Authors were contacted for missing outcome data when it was indicated that an outcome was measured but not reported. In the absence of numerical values for outcome measurements and inability to obtain the original data from authors, values were extracted from figures using Plot Digitizer where available. ${ }^{1}$ All discrepancies between reviewers were resolved through consensus or, where necessary, arbitration by the senior author.

\section{Study quality}

Included studies were assessed for risk of bias by at least two of the reviewers using the Cochrane Collaboration risk of bias tool ${ }^{27}$. Final assessments were based on consensus between reviewers.

\section{Data synthesis and analysis}

We used Review Manager (RevMan) version 5.2 for primary analyses and Stata (version 12) for subgroup, dose response, and publication bias analyses. We performed separate analyses for the four prespecified study designs based on the control of energy (substitution, addition, subtraction, and ad libitum studies), and stratified analyses by food sources of sugars for each of three outcome variables (HbA1c, fasting blood glucose, and fasting blood insulin). The principal effect measure was the mean pairwise difference in change from baseline (or, when not available, the post-treatment value) between the food sources of the fructose-containing sugars arm and the comparator arm (reporting results as mean differences with 95\% confidence intervals). We extracted the estimates of the mean differences and corresponding 95\% confidence intervals for each outcome. Changefrom-baseline differences were preferred over end differences, and paired analyses were applied to all crossover trials with the use of a within-individual correlation coefficient between treatments of 0.5 as described by Elbourne and colleagues. ${ }^{28}$

When at least two studies provided data, we performed a DerSimonian and Laird random effects meta-analysis. When fewer than five studies were available for analysis, we also considered fixed effect estimates. Heterogeneity was assessed by the Cochran $\mathrm{Q}$ test (significant at $\mathrm{P}<0.10$ ) and quantified by the $\mathrm{I}^{2}$ statistic (range $0-100 \%$ ). ${ }^{29}$ The interaction between fructose-containing sugars and food source was assessed by use of the $\chi^{2}$ statistic. Other sources of heterogeneity were explored by sensitivity and subgroup analyses. We carried out sensitivity analyses by systematically removing each study from the metaanalyses and recalculating the summary association. A study whose removal explained the heterogeneity, changed the significance of the effect, or altered the effect size by $10 \%$ or more was considered an influential study. If 10 or more studies per outcome were available, ${ }^{30} 31$ we conducted a priori subgroup analyses using meta-regression. Categorical subgroup analyses were done for energy balance (positive, neutral, negative), comparator (starch, glucose, fat, lactose, maltrodextrin, diet alone, water, non-nutritive sweeteners, protein, mixed sources), fructosecontaining sugars type (fruit, sucrose, fructose, HFCS, honey), fructose-containing sugars dose $(\leq 10 \%$, $>10 \%$ energy $\left.^{22} 32\right)$, baseline HbA1c values $(\leq 7 \%$, $>7 \%)$, fasting glucose $(\leq 5.5,>5.5 \mathrm{mmol} / \mathrm{L}$ based on median values) and insulin $(\leq 96.6,>96.6 \mathrm{pmol} / \mathrm{L}$ based on median values), age ( $\leq 18,>18$ years), study design (crossover, parallel), follow-up duration $(<8, \geq 8$ weeks), randomisation (yes, no), level of feeding control (supplemented, dietary advice, and metabolically controlled), underlying disease status (diabetes, overweight/obese, metabolic syndrome criteria, otherwise healthy), and individual domains of risk of bias (sequence generation, allocation concealment, blinding of participants/personnel and outcome assessors, incomplete outcome data, selective outcome reporting).

We performed continuous dose-response analyses using meta-regression to assess linear dose-response gradients and non-linear meta-regression (MKSPLINE procedure) with knots at the public health thresholds 
of $5 \%,,^{22} 2310 \%,{ }^{2233}$ and $25 \%{ }^{34}$ energy, to assess nonlinear dose-threshold effects. If 10 or more studies per outcome were available, ${ }^{35}$ we assessed publication bias by inspection of funnel plots and formal testing with the Egger and Begg tests. If we saw evidence of publication bias, we used the Duval and Tweedie trim and fill method to adjust for funnel plot asymmetry by imputing missing study data. ${ }^{36}$

\section{Grading of the evidence}

We used the GRADE approach (grading of recommendations assessment, development, and evaluation) to assess the certainty in our estimates and produce evidence profiles ${ }^{37}$ using GRADEpro GDT (GRADEpro Guideline Development Tool software, McMaster University, Canada, 2015). Evidence was graded as high, moderate, low, or very low quality. Included controlled intervention studies were graded as high quality evidence by default and downgraded on the basis of prespecified criteria. Criteria to downgrade evidence included risk of bias (assessed by the Cochrane risk of bias tool), inconsistency (substantial unexplained heterogeneity, $\mathrm{I}^{2}>50 \%$, $\mathrm{P}<0.10$ ), indirectness (presence of factors that limited the generalisability of the results), imprecision (if the 95\% confidence interval for pooled effect estimates crossed a minimally important difference for benefit or harm for $\mathrm{HbA1c}(0.3 \%$ difference), fasting blood glucose ( $0.5 \mathrm{mmol} / \mathrm{L}$ difference), and fasting blood insulin (10 pmol/L difference)), and publication bias (significant evidence of publication bias).

\section{Patient and public involvement}

Patient and public involvement was not included in this study. We were unable to involve any patients or members of the public in the design or conduct of the study, development of patient relevant outcomes, interpretation of the results, or writing or editing of the manuscript.

\section{Results}

\section{Search results}

Figure 1 shows the systematic search and selection of literature. Of 4442 reports identified from database and manual searches, 4157 were excluded on the basis of the title and abstract. Of 285 reports reviewed in full, an additional 164 reports were excluded for failure to meet the eligibility criteria. The final analysis included 118 reports of controlled intervention studies, 51112 38-152 including a total of 155 study comparisons in 5086 participants.

\section{Study characteristics}

Table 1 provides a summary of the mean study characteristics by the four prespecified study designs (substitution, addition, subtraction, and ad libitum studies), with a breakdown of individual study characteristics in supplementary table 2. Study sizes were relatively small, ranging from a median of 15 participants (range 6-318) in subtraction studies to 39 participants (8-236) in ad libitum studies. Most studies were performed in an outpatient setting, with almost half of all substitution (43/108), addition (12/35), and subtraction (1/5) studies conducted in the US, and all ad libitum studies conducted in European countries. Participants tended to be middle aged, with roughly equal ratios of men to women in substitution, addition, and ad libitum studies, but proportionately more women than men in subtraction studies. Most studies included individuals with diabetes $(34 \%, 37 / 108)$ or otherwise healthy participants $(26 \%, 28 / 108)$ in substitution studies; otherwise healthy $(34 \%, 12 / 35)$ or overweight or obese participants $(29 \%, 10 / 35)$ in addition studies; overweight or obese participants $(80 \%, 4 / 5)$ in subtractions studies; and otherwise healthy participants $(43 \%, 3 / 7)$ in ad libitum studies.

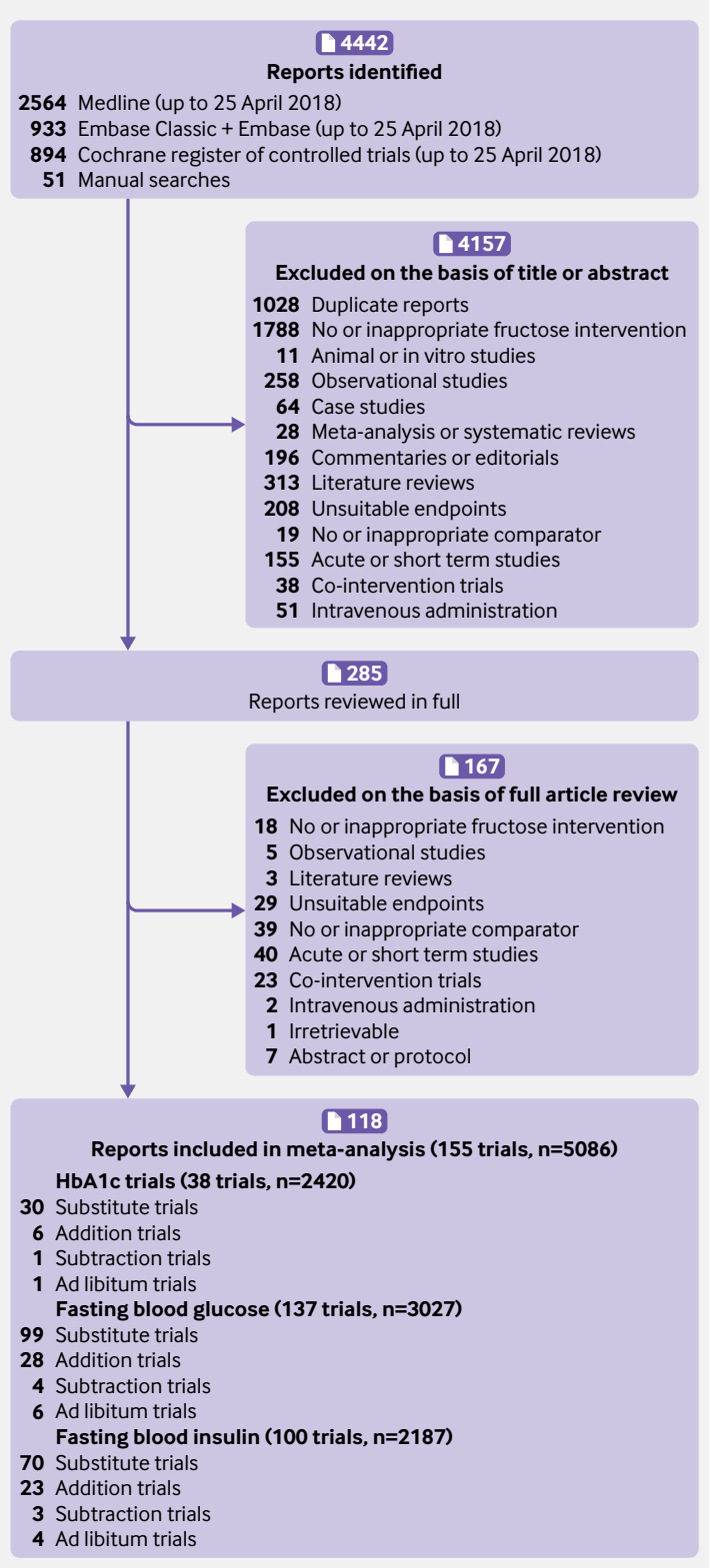

Fig 1 | Flow of literature for the effect of food sources of fructose-containing sugars on glycaemic control 


\begin{tabular}{|c|c|c|c|c|}
\hline Study characteristics & Substitution studies & Addition studies & Subtraction studies & Ad libitum studies \\
\hline Study comparisons (No) & 108 & 35 & 5 & 7 \\
\hline Study size (median No (range) of participants) & $15(5-595)$ & $20(6-63)$ & $15(6-318)$ & $39(8-236)$ \\
\hline Men:women ratio (\%) & $42: 58$ & 46:54 & $12: 88$ & 41:59 \\
\hline Age (years; median (interquartile range)) & $39.8(24.7-53.8)$ & $36.2(27.4-49.4)$ & $33.5(29.1-41.9)$ & $38(34-39.8)$ \\
\hline $\begin{array}{l}\text { Setting (\%; inpatients, outpatients, } \\
\text { inpatients/outpatients) }\end{array}$ & $10,75,15$ & $3,89,9$ & $0,100,0$ & $0,100,0$ \\
\hline $\begin{array}{l}\text { Baseline fasting glucose (mmol/L; median } \\
\text { (interquartile range)) }\end{array}$ & $5.4(4.9-8.5)$ & $5.1(4.9-5.4)$ & $5.1(5.1-5.2)$ & $4.9(4.9-5.4)$ \\
\hline $\begin{array}{l}\text { Baseline fasting insulin (pmol/L; median } \\
\text { (interquartile range)) }\end{array}$ & $96.6(57.9-128.5)$ & $50.4(40.6-81.4)$ & $109.8(97.8-121.7)$ & $32.8(32.1-45.9)$ \\
\hline $\begin{array}{l}\text { Baseline } \mathrm{HbA} 1 \mathrm{c}(\% \text {; median (interquartile } \\
\text { range)) }\end{array}$ & $7.5(6.8-8.5)$ & $6.8(5.5-7.1)$ & $\begin{array}{l}\text { Baseline data only } \\
\text { reported for one study }\end{array}$ & $\begin{array}{l}\text { Baseline data only } \\
\text { reported for one study }\end{array}$ \\
\hline Study design (\%; crossover:parallel) & $61: 39$ & 49: 51 & 20: 80 & $57: 43$ \\
\hline Feeding control (\%; met, supp, DA) & $44,41,16$ & $13,80,7$ & $0,70,30$ & $50,37.5,12.5$ \\
\hline Randomisation (\%; yes:no) & $72: 28$ & $66: 34$ & $80: 20$ & $100: 0$ \\
\hline $\begin{array}{l}\text { Fructose-containing sugar dose (\% of total } \\
\text { energy intake; median (interquartile range)) }\end{array}$ & $15.0(9.3-22.1)$ & $12.2(7.7-25.0)$ & $15.0(11.3-15.0)$ & $23.0(13.0-26.0)$ \\
\hline $\begin{array}{l}\text { Follow-up duration (median No (range) of } \\
\text { weeks) }\end{array}$ & $4.5(1-52)$ & $6(1-24)$ & $12(1-36)$ & $8(2-76)$ \\
\hline $\begin{array}{l}\text { Funding sources (\%; ag, ind, ag-ind, not } \\
\text { reported) }\end{array}$ & $32,18,28,22$ & $49,9,34,9$ & $60,40,0,0$ & $0,17,50,33$ \\
\hline Fructose-containing sugar type (No of studies) & $\begin{array}{l}\text { Fructose }=47, \text { fruit }=17, \mathrm{HFCS}=3 \text {, } \\
\text { sucrose }=48, \text { honey }=2\end{array}$ & $\begin{array}{l}\text { Fructose }=8 \text {, fruit }=13, \mathrm{HFCS}=1 \text {, } \\
\text { honey }=4 \text {, sucrose }=9\end{array}$ & Sucrose $=5, \mathrm{HFCS}=4$ & Fructose $=1$, sucrose $=7$ \\
\hline Comparator (No of studies) & $\begin{array}{l}\text { Fat }=7 \text {, glucose }=23 \text {, lactose }=5 \text {, } \\
\text { maltodextrin }=1 \text {, mixed compara- } \\
\text { tor }=14 \text {, protein }=1 \text {, starch }=53 \text {, diet } \\
\text { alone }=3 \text {, water }=1\end{array}$ & $\begin{array}{l}\text { Diet alone }=27 \text {, sweetener }=4 \text {; } \\
\text { water }=5\end{array}$ & $\begin{array}{l}\text { Water }=2 \text {, } \\
\text { sweetener }=3 \text {, } \\
\text { no } \text { sucrose }=1\end{array}$ & $\begin{array}{l}\text { Fat }=2, \text { mixed } \\
\text { comparator=2, } \operatorname{starch}=4 \text {, } \\
\text { sweetener }=3\end{array}$ \\
\hline $\begin{array}{l}\text { Food sources of } \\
\text { fructose-containing sugars (No of studies) }\end{array}$ & $\begin{array}{l}\text { Fruit=12; dried fruit=4; fruit juice=1; } \\
\text { SSBs=21; sweetened low fat } \\
\text { milk=2; baked goods, sweets, and } \\
\text { desserts=11; added sweeteners=12; } \\
\text { mixed sources }=45\end{array}$ & $\begin{array}{l}\text { Fruit=9; dried fruit=1; fruit juice }=3 ; \\
\text { fruit drink=3; } S S B s=12 ; \text { sweetened } \\
\text { chocolate=1; baked goods, sweets, } \\
\text { and desserts=1; added } \\
\text { sweeteners=4; } \text { mixed sources }=1\end{array}$ & $\begin{array}{l}\text { Mixed sources }=1 \\
\mathrm{SSBS}=4\end{array}$ & $\begin{array}{l}\text { Baked goods, sweets, } \\
\text { and desserts }=1 \text {; mixed } \\
\text { sources }=6\end{array}$ \\
\hline
\end{tabular}

Most studies were randomised $(72 \%$ (78/108) of substitution studies, $66 \%(23 / 35)$ of addition studies, $80 \%$ (4/5) of subtraction studies, and 100\% (7/7) of ad libitum studies). Follow-up duration was relatively short, ranging from a median of 4.5 weeks (range 1-52 weeks) in substitution studies to 12 weeks (1-36) in subtraction studies. Doses of fructosecontaining sugars ranged from a median of $12.2 \%$ (range 7.7-25.0\%) of total energy intake in addition studies to $23 \%$ (13.0-26.0\%) in ad libitum studies, and were mostly in the form of mixed food sources in substitution (45/108) and ad libitum (6/7) studies while most addition studies (12/35) and subtraction studies (4/5) used SSBs. Most studies were funded by agency sources (government, not-for-profit health agency, or university sources), except for ad libitum trials, which were primarily funded by agency-industry funding.

\section{Study quality}

Supplementary figure 1 shows a summary of the risk of bias assessments by the Cochrane risk of bias tool. Owing to poor reporting standards, most studies were assessed as having unclear risk of bias across the five domains of bias. Few studies were assessed as having high risk of bias, with only $20.3 \%$ (24/118), $23.7 \%$ (28/118), $1.7 \%$ (2/118), 8.5\% (10/118) of studies assessed as high risk of bias for random sequence generation, allocation concealment, blinding of participants and personnel, and incomplete outcome data, respectively. Overall, no serious risk of bias was detected.

\section{Outcomes}

\section{HbA1c}

Figure 2 and supplementary figures $2-5$ show the effect of different food sources of fructose-containing sugars on HbA1c levels. Total fructose-containing sugars independent of food sources showed a significant beneficial effect on HbA1c in substitution studies (30 study comparisons, mean difference $-0.22 \%(95 \%$ confidence interval $-0.35 \%$ to $-0.08 \%),-25.9 \mathrm{mmol} /$ mol (95\% confidence interval -27.3 to -24.4$), \mathrm{P}<0.01$, substantial heterogeneity $\left.\left(\mathrm{I}^{2}=82 \%, \mathrm{P}<0.001\right)\right)$. We saw no significant effect in addition studies (six study comparisons, substantial heterogeneity $\left(\mathrm{I}^{2}=83 \%\right.$, $\mathrm{P}<0.001)$ ), subtraction studies (one study comparison), or ad libitum studies (one study comparison). Although formal tests of interaction by food source were not significant in the substitution or addition studies, an interaction appeared to be present in the substitution studies, with fruit being the major driver of the effect. Fruit accounted for $30 \%$ of the weighted benefit as the only food source, showing a significant decrease in HbA1c (six study comparisons, mean difference $-0.19 \%$ ( $95 \%$ confidence interval -0.35 to -0.03 ), $-25.6 \mathrm{mmol} / \mathrm{mol}(95 \%$ confidence interval -27.3 to -23.8), $\mathrm{P}=0.02$, substantial heterogeneity $\left(\mathrm{I}^{2}=78 \%\right.$, 


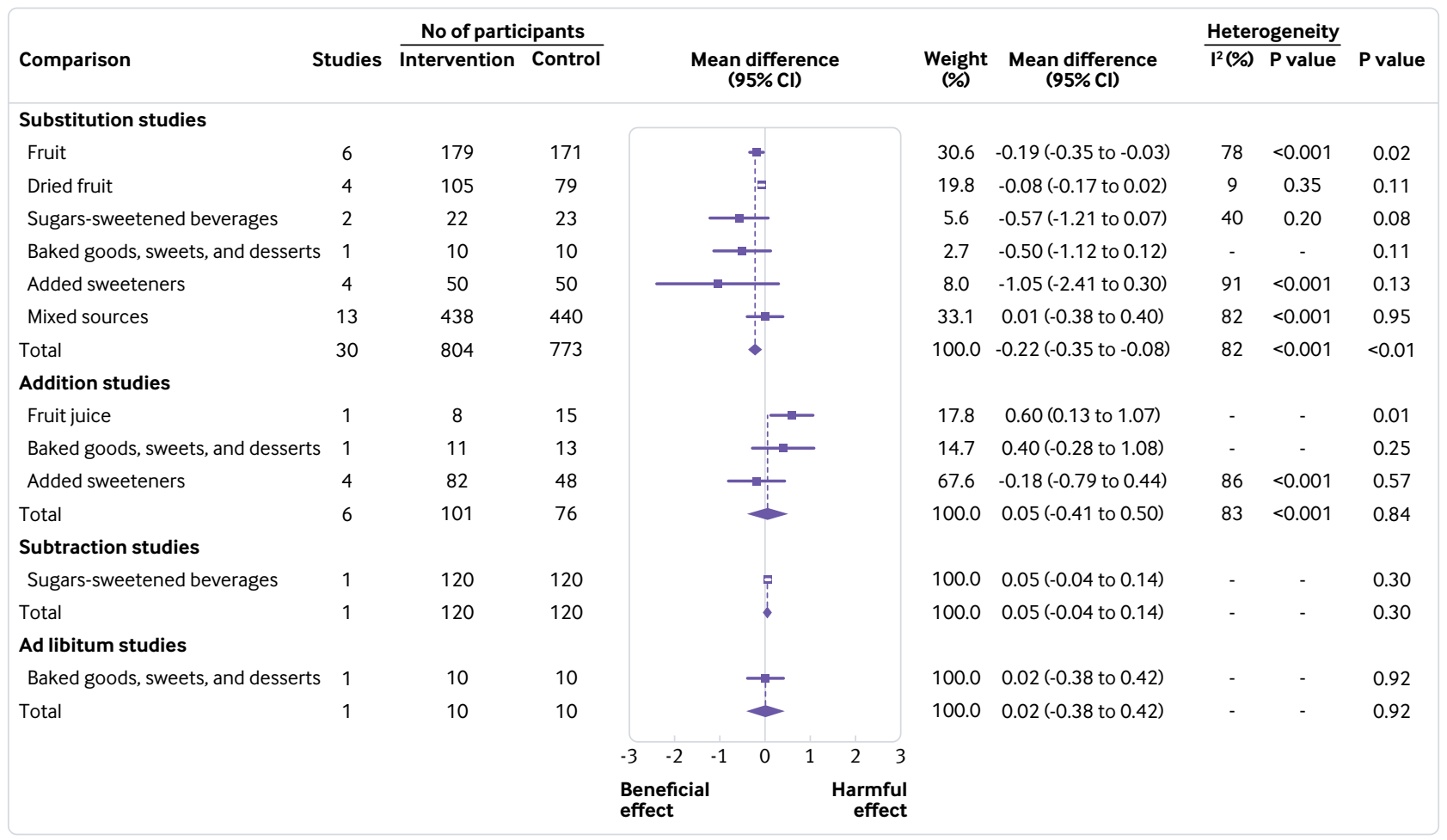

Fig 2 | Summary plot for the effect of food sources of fructose-containing sugars on glycated haemoglobin (HbA1c). Data are weighted mean differences ( $95 \%$ confidence intervals) for summary effects of individual food sources and total food sources on HbA1c. Analyses conducted by generic, inverse variance random effects models (at least five trials available) or fixed effects models (fewer than five trials available). Interstudy heterogeneity was tested by the Cochran's $Q$ statistic $\left(x^{2}\right)$ at a significance level of $P<0.10$

$\mathrm{P}<0.001)$ ). An interaction by food source could not be assessed at the other levels of energy control, because only one food source category was assessed in the subtraction studies (SSBs) and ad libitum studies (baked goods, sweets, and desserts).

Sensitivity analyses for $\mathrm{HbA1c}$ are presented in supplementary table 3 . The removal of each study did not explain the heterogeneity or change the significance of the effect. A priori subgroup analyses for $\mathrm{HbA} 1 \mathrm{c}$ are presented in supplementary figures 6 and 7 and dose-response analyses for $\mathrm{HbA} 1 \mathrm{c}$ are presented in supplementary figures 8 and 9. A priori subgroup analyses did not show any effect modification in substitution studies. We saw evidence of a dose threshold seen at $10 \%$ energy by MKSPLINE procedure with the largest decreases seen only at doses up to $10 \%$ energy $(\mathrm{P}=0.04)$. No subgroup or dose-response analyses were conducted for addition, subtraction, or ad libitum studies, because fewer than 10 studies were available for analyses.

\section{Fasting blood glucose}

Figure 3 and supplementary figures $10-13$ show the effect of different food sources of fructose-containing sugars on fasting blood glucose. Total fructosecontaining sugars independent of food sources had no effect on fasting blood glucose in substitution studies (99 study comparisons, substantial heterogeneity $\left(\mathrm{I}^{2}=65 \%, \mathrm{P}<0.001\right)$ ), addition studies (28, substantial heterogeneity $\left.\left(\mathrm{I}^{2}=71 \%, \mathrm{P}<0.001\right)\right)$, subtraction studies (four, substantial heterogeneity $\left(\mathrm{I}^{2}=59 \%, \mathrm{P}=0.06\right)$ ), or adlibitumstudies(six, noevidenceofheterogeneity).We saw a significant interaction by food source in addition studies $(\mathrm{P}=0.01)$ : SSBs (11 study comparisons, mean difference $0.12 \mathrm{mmol} / \mathrm{L}$ (95\% confidence interval 0.03 to 0.22$)$, substantial heterogeneity $\left.\left(\mathrm{I}^{2}=74 \%\right), \mathrm{P}<0.001\right)$ and fruit juice (two, $0.29 \mathrm{mmol} / \mathrm{L}(0.09$ to 0.49$)$, no evidence of heterogeneity) showed a significant harmful effect. However, fruit (six study comparisons), dried fruit (one study comparison), fruit drinks (three), sweetened chocolate (one), added sweeteners (three), and mixed sources (one) showed no significant effect on fasting blood glucose. No significant interaction by food source was seen in the substitution, subtraction, or ad libitum studies, although only one food source category was assessed in the subtraction studies (SSBs) and ad libitum studies (mixed sources).

Supplementary table 3 shows the sensitivity analyses for fasting blood glucose. Removal of any one of six addition studies 384672105114123 changed the estimates from non-significant to significant, but did not change the magnitude or direction of the effect or the evidence of substantial heterogeneity. Removal of the 2015 subtraction study by Campos and colleagues (group 2) ${ }^{60}$ explained all of the heterogeneity, changing the direction but not the lack of significance of the effect on fasting blood glucose. Finally, removal of the 2012 subtraction study by Tate and colleagues ${ }^{148}$ explained most of the heterogeneity $\left(\mathrm{I}^{2}=32 \%, \mathrm{P}=0.23\right)$ but did not change the direction or lack of significance of the effect on fasting blood glucose. 


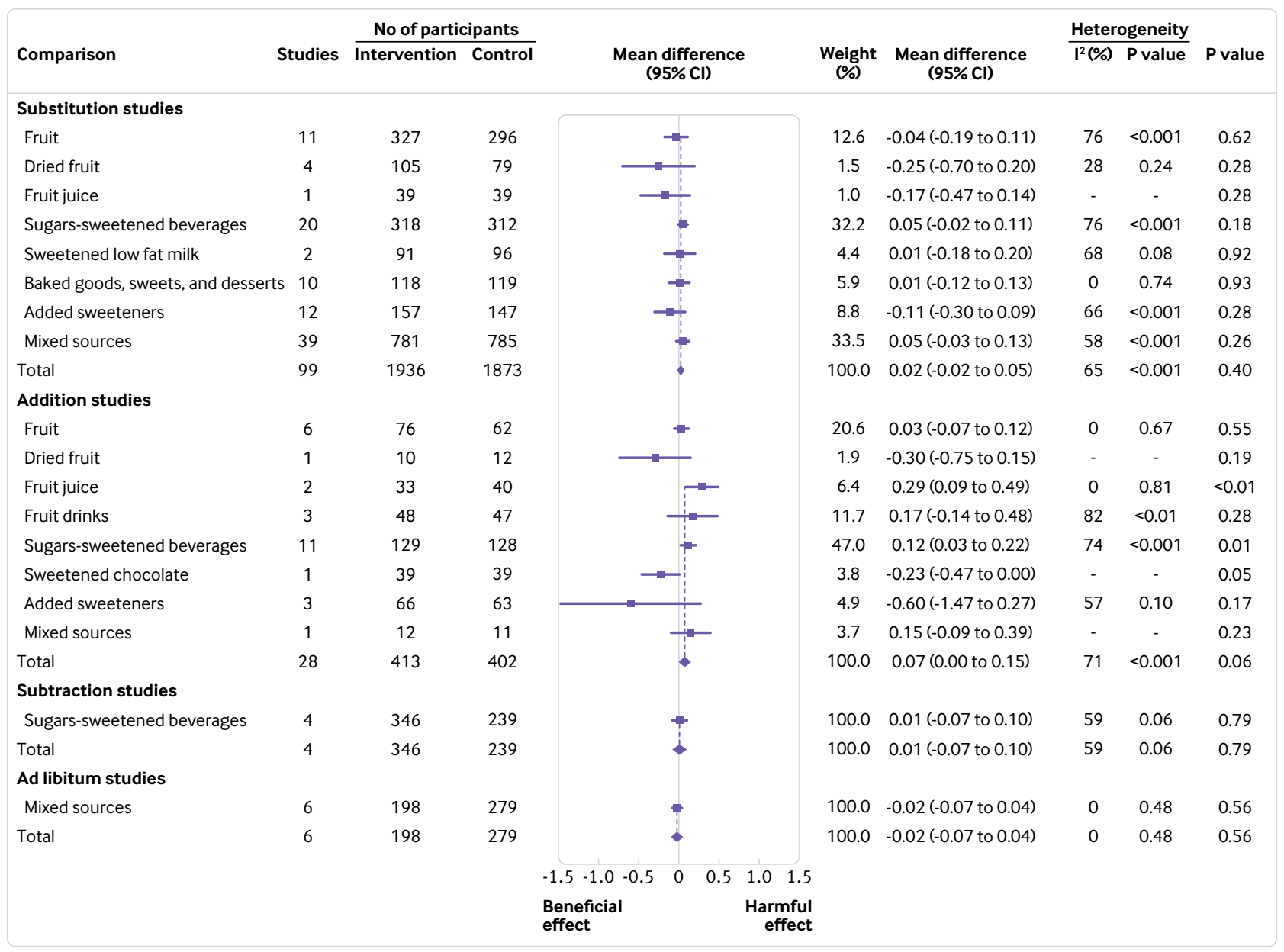

Fig 3 | Summary plot for the effect of food sources of fructose-containing sugars on fasting blood glucose. Data are weighted mean differences ( $95 \%$ confidence intervals) for summary effects of individual food sources and total food sources on fasting blood glucose. Analyses conducted by generic, inverse variance random effects models (at least five trials available) or fixed effects models (fewer than five trials available). Interstudy heterogeneity was tested by the Cochran's $Q$ statistic $\left(x^{2}\right)$ at a significance level of $P<0.10$

A priori subgroup analyses for fasting blood glucose are presented in supplementary figures $14-17$, and dose-response analyses for fasting blood glucose are presented in supplementary figures 8 and 9. We saw significant effect modification by dose of fructose-containing sugars $(\leq 10 \%$ energy or $>10 \%$ energy), with a further threshold effect ( $25 \%$ energy) identified by the MKSPLINE procedure, comparator (starch, glucose, fat, mixed, lactose, dairy), baseline fasting blood glucose $(\leq 5.5 \mathrm{mmol} / \mathrm{L}$ or $>5.5 \mathrm{mmol} / \mathrm{L})$, feeding control (dietary advice, supplementation, or metabolically controlled), or underlying disease status (otherwise healthy, overweight/obese, diabetes, metabolic syndrome, or non-alcoholic fatty liver disease) in the substitution studies $(\mathrm{P}<0.05)$. We also observed a significant subgroup effect by baseline fasting blood glucose $(\leq 5.5 \mathrm{mmol} / \mathrm{L}$ or $>5.5 \mathrm{mmol} / \mathrm{L})$ in addition studies $(\mathrm{P}=0.01)$. None of the subgroup or dose-response analyses explained the substantial heterogeneity in the substitution and addition studies. No subgroup or dose-response analyses were conducted for subtraction or ad libitum comparisons because fewer than 10 studies were available for analyses.

\section{Fasting blood insulin}

Figure 4 and supplementary figures 18-21 show the effect of different food sources of fructose-containing sugars on fasting blood insulin. Total fructose-containing sugars independent of food sources had a harmful effect on fasting blood insulin in addition studies (23 study comparisons, mean difference $4.68 \mathrm{pmol} / \mathrm{L}$ (95\% confidence interval 1.40 to 7.96 ), $\mathrm{P}<0.01$, substantial heterogeneity $\left.\left(\mathrm{I}^{2}=58 \%, \mathrm{P}<0.001\right)\right)$ and ad libitum studies (four, $7.24 \mathrm{pmol} / \mathrm{L}$ (0.47 to 14.00), $\mathrm{P}=0.04$, no evidence of heterogeneity $\left(\mathrm{I}^{2}=0 \%\right.$, $\mathrm{P}=0.46)$ ). We saw no effect in substitution studies $(70$ studies, substantial heterogeneity $\left.\left(\mathrm{I}^{2}=61 \%, \mathrm{P}<0.001\right)\right)$ or subtraction (three, substantial heterogeneity $\left.\left(\mathrm{I}^{2}=79 \%, \mathrm{P}<0.01\right)\right)$.

We saw a significant interaction by food source in substitution studies $(\mathrm{P}<0.001)$. Fruit juice (one study comparison, mean difference $-13.89 \mathrm{pmol} / \mathrm{L}(95 \%$ confidence interval -27.50 to -0.28$), \mathrm{P}=0.05$ ) showed a beneficial effect, and sweetened low fat milk (two, $18.95 \mathrm{pmol} / \mathrm{L}$ (9.09 to 28.80), $\mathrm{P}<0.001$, no evidence of heterogeneity) and mixed sources (25, $7.74 \mathrm{pmol} / \mathrm{L}$ (2.94 to 12.53 ), $\mathrm{P}<0.01$, no substantial heterogeneity) showed a harmful effect. Fruit (six study comparisons, 


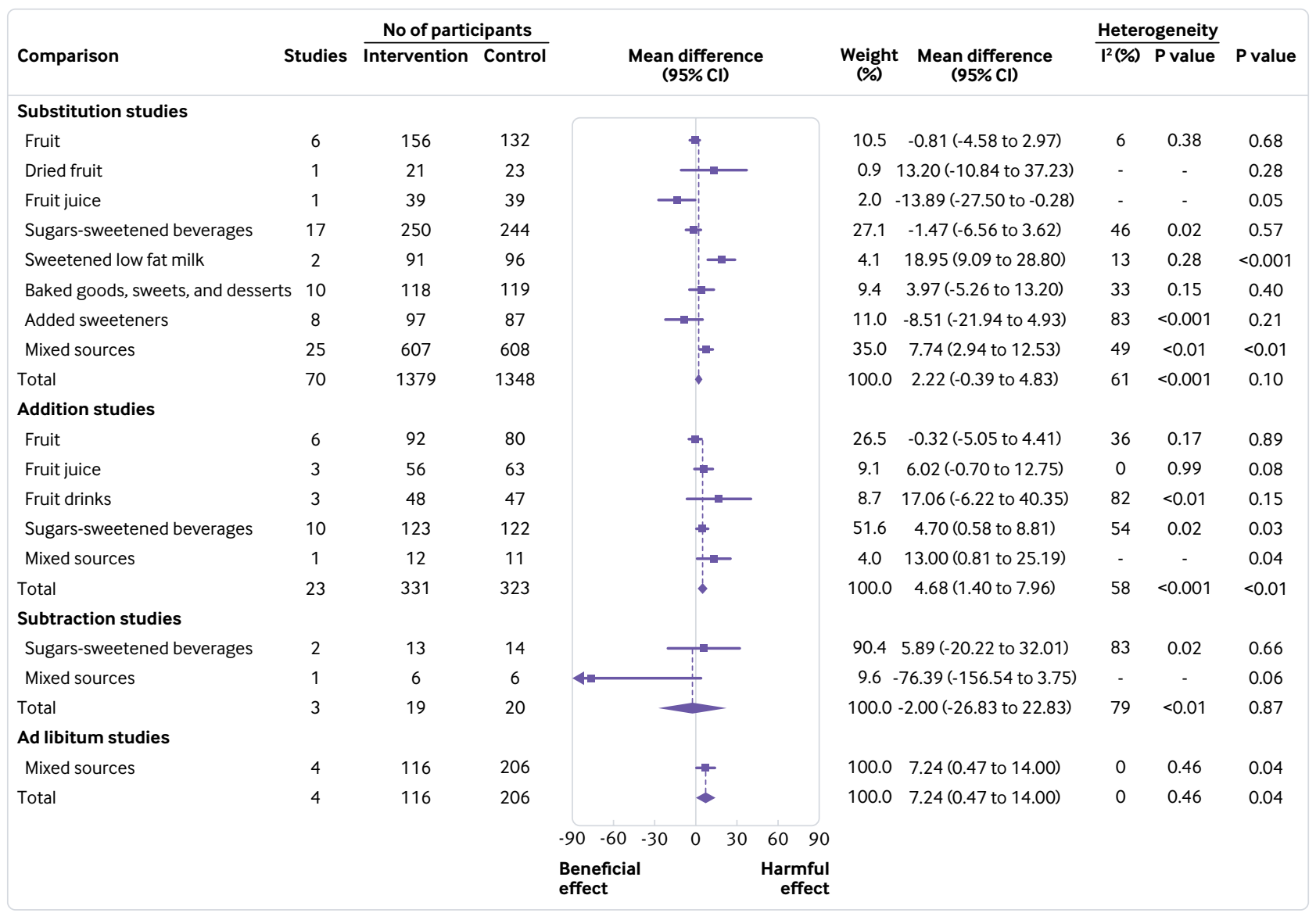

Fig 4 | Summary plot for the effect of food sources of fructose-containing sugars on fasting blood insulin. Data are weighted mean differences ( $95 \%$ confidence intervals) for summary effects of individual food sources and total food sources on fasting blood insulin. Analyses conducted by generic, inverse variance random effects models (at least five trials available) or fixed effects models (fewer than five trials available). Interstudy heterogeneity was tested by the Cochran $Q$ statistic $\left(x^{2}\right)$ at a significance level of $P<0.10$

no evidence of heterogeneity); dried fruit (one); SSBs (17); baked goods, sweets, and desserts (10, no evidence of heterogeneity); and added sweeteners (eight, substantial heterogeneity $\left(\mathrm{I}^{2}=83, \mathrm{P}<0.001\right)$ ) showed no significant effect on fasting blood insulin. No significant interaction by food source was seen in the addition, ad libitum, or subtraction studies, although SSBs accounted for more than $50 \%$ of the weighted harm in addition studies and mixed sources was the exclusive food source of fructose-containing sugars in the ad libitum studies.

Sensitivity analyses for fasting blood insulin are presented in supplementary table 3. Removal of the 2009 addition study by Hollis and colleagues ${ }^{83}$ explained some of the heterogeneity $\left(\mathrm{I}^{2}=42 \%, \mathrm{P}=0.02\right)$ without changing the significance, magnitude, or direction of the effect. Removal of either one of two substitution studies ${ }^{92104}$ changed the evidence from non-significant to significant without changing the magnitude or direction of the effect or the evidence of substantial heterogeneity. Removal of the subtraction study by Campos and colleagues (group 2$)^{60}$ explained nearly all of the heterogeneity $\left(\mathrm{I}^{2}=1 \%, \mathrm{P}=0.31\right)$, changing the significance and magnitude but not the direction of the effect. Removal of the 2000 ad libitum study by Raben and colleagues $(C)^{124}$ eliminated the evidence for the significance but not the direction of the effect or evidence of no substantial heterogeneity.

A priori subgroup analyses for fasting blood insulin are presented in supplementary figures 22-25, and dose-response analyses for fasting blood insulin are presented in supplementary figures 8 and 9. We saw significant effect modification in substitution studies by level of feeding control (dietary advice, supplementation, or metabolically controlled) or by risk of bias for blinding of participants, personnel, and outcome assessors (low, high, or unclear) in the substitution studies $(\mathrm{P}<0.05)$. None of the subgroup or dose-response analyses explained the substantial heterogeneity in the substitution studies. No subgroup or dose-response analyses were significant in the addition studies. No subgroup analyses were conducted for the subtraction or ad libitum studies, because fewer than 10 studies were available for analyses.

\section{Publication bias}

Supplementary figures 26 and 27 show the publication bias assessment for all analyses where at least 10 studies were available. We saw no evidence of publication bias for the effect of food sources of fructose containing sugars on $\mathrm{HbA} 1 \mathrm{c}$, fasting blood glucose, or fasting blood insulin. Although the Begg test was 


\begin{tabular}{|c|c|c|c|c|c|c|c|}
\hline \multirow{2}{*}{$\begin{array}{l}\text { Type and No of } \\
\text { studies }\end{array}$} & \multirow[b]{2}{*}{ Study design } & \multicolumn{5}{|c|}{ Quality assessment } & \multirow[b]{2}{*}{ Quality } \\
\hline & & Risk of bias & Inconsistency & Indirectness & Imprecision & Other considerations & \\
\hline \multicolumn{8}{|l|}{$\mathrm{HbA1c}$} \\
\hline Substitution $(n=30)$ & $\begin{array}{l}\text { Randomised and } \\
\text { non-randomised }\end{array}$ & $\begin{array}{l}\text { No serious } \\
\text { risk of bias }\end{array}$ & Serious* & No serious indirectness & Serious* & None & $\begin{array}{l}\oplus \oplus \mathrm{OO} \\
\text { Low }\end{array}$ \\
\hline Addition $(n=6)$ & $\begin{array}{l}\text { Randomised and } \\
\text { non-randomised }\end{array}$ & $\begin{array}{l}\text { No serious } \\
\text { risk of bias }\end{array}$ & Serioust & No serious indirectness & Serioust & None & $\begin{array}{l}\oplus \oplus \mathrm{OO} \\
\text { Low }\end{array}$ \\
\hline Subtraction $(\mathrm{n}=1)$ & $\begin{array}{l}\text { Randomised and } \\
\text { non-randomised }\end{array}$ & $\begin{array}{l}\text { No serious } \\
\text { risk of bias }\end{array}$ & No serious inconsistency $\neq$ & Serious§ & Serious§ & None $\neq$ & $\begin{array}{l}\oplus \oplus \mathrm{OO} \\
\text { Low }\end{array}$ \\
\hline Ad libitum $(n=1)$ & $\begin{array}{l}\text { Randomised and } \\
\text { non-randomised }\end{array}$ & $\begin{array}{l}\text { No serious } \\
\text { risk of bias }\end{array}$ & No serious inconsistency $\ddagger$ & Serious $\mathbb{1}$ & Serious & Noneł & $\begin{array}{l}\oplus \oplus \mathrm{OO} \\
\text { Low }\end{array}$ \\
\hline \multicolumn{8}{|l|}{ Fasting blood glucose } \\
\hline Substitution $(\mathrm{n}=99)$ & $\begin{array}{l}\text { Randomised and } \\
\text { non-randomised }\end{array}$ & $\begin{array}{l}\text { No serious } \\
\text { risk of bias }\end{array}$ & Serious $^{\star \star}$ & No serious indirectness & Serious $^{\star *}$ & None & $\begin{array}{l}\oplus \oplus \mathrm{OO} \\
\text { Low }\end{array}$ \\
\hline Addition $(n=28)$ & $\begin{array}{l}\text { Randomised and } \\
\text { non-randomised }\end{array}$ & $\begin{array}{l}\text { No serious } \\
\text { risk of bias }\end{array}$ & Serioust† & No serious indirectness & Serioust† & None & $\begin{array}{l}\oplus \oplus \mathrm{OO} \\
\text { LoW }\end{array}$ \\
\hline Subtraction $(n=4)$ & $\begin{array}{l}\text { Randomised and } \\
\text { non-randomised }\end{array}$ & $\begin{array}{l}\text { No serious } \\
\text { risk of bias }\end{array}$ & No serious inconsistencył & No serious indirectness & Serious $\ddagger \ddagger$ & None $\neq$ & $\begin{array}{l}\oplus \oplus \oplus \mathrm{O} \\
\text { Moderate }\end{array}$ \\
\hline Ad libitum $(n=6)$ & $\begin{array}{l}\text { Randomised and } \\
\text { non-randomised }\end{array}$ & $\begin{array}{l}\text { No serious } \\
\text { risk of bias }\end{array}$ & No serious inconsistency & No serious indirectness & Serious§§ & Noneł & $\begin{array}{l}\oplus \oplus \oplus \mathrm{O} \\
\text { Moderate }\end{array}$ \\
\hline \multicolumn{8}{|l|}{ Fasting blood insulin } \\
\hline Substitution $(n=70)$ & $\begin{array}{l}\text { Randomised and } \\
\text { non-randomised }\end{array}$ & $\begin{array}{l}\text { no serious } \\
\text { risk of bias }\end{array}$ & Serious & No serious indirectness & Serious & None & $\begin{array}{l}\oplus \oplus \mathrm{OO} \\
\text { Low }\end{array}$ \\
\hline Addition $(n=23)$ & $\begin{array}{l}\text { Randomised and } \\
\text { non-randomised }\end{array}$ & $\begin{array}{l}\text { No serious } \\
\text { risk of bias }\end{array}$ & Serious ${ }^{\star \star \star}$ & No serious indirectness & Serious ${ }^{\star \star \star}$ & None & $\begin{array}{l}\oplus \oplus \oplus \mathrm{OO} \\
\text { LoW }\end{array}$ \\
\hline Subtraction $(n=3)$ & $\begin{array}{l}\text { Randomised and } \\
\text { non-randomised }\end{array}$ & $\begin{array}{l}\text { No serious } \\
\text { risk of bias }\end{array}$ & Serioustt† & No serious indirectness & Seriousttt & Noneł & $\begin{array}{l}\oplus \oplus \oplus \mathrm{OO} \\
\text { LoW }\end{array}$ \\
\hline Ad libitum $(n=4)$ & $\begin{array}{l}\text { Randomised and } \\
\text { non-randomised }\end{array}$ & $\begin{array}{l}\text { No serious } \\
\text { risk of bias }\end{array}$ & No serious inconsistency & No serious indirectness & 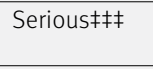 & Noneł & $\begin{array}{l}\oplus \oplus \oplus \mathrm{O} \\
\text { Moderate }\end{array}$ \\
\hline
\end{tabular}

GRADE= grading of recommendations assessment, development, and evaluation; Hb1Ac=glycated haemoglobin; MID=minimally important difference.

*Serious inconsistency-evidence of significant interstudy heterogeneity; $\left.\left.\right|^{2}=82 \%, P<0.001\right)$; serious imprecision $-95 \%$ confidence interval ( $-0.35 \%$ to $-0.08 \%,-27.3$ to

$-24.4 \mathrm{mmol} / \mathrm{mol})$ overlaps the MID for $\mathrm{HbA} 1 \mathrm{c}(0.3 \%)$, including clinically unimportant benefit $(\geq-0.3 \%)$.

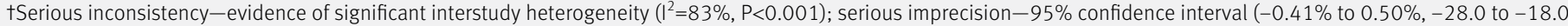
$\mathrm{mmol} / \mathrm{mol}$ ) overlaps the MID for HbA1c (0.3\%), including both clinically important benefit $(\leq-0.3 \%)$ and harm $(\geq 0.3 \%)$.

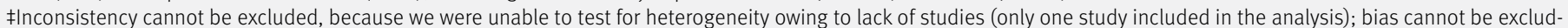
ed, because we were unable to test for funnel plot asymmetry owing to lack of power (<10 studies included in the analysis).

§Serious indirectness-only one study of 240 overweight/obese female participants was available for analysis; serious imprecision-95\% confidence interval ( $-0.04 \%$ to $0.14 \%,-23.9$ to $-22.0 \mathrm{mmol} / \mathrm{mol})$ overlaps the MID for HbA1c $(0.3 \%)$, including clinically unimportant benefit ( $\geq-0.3 \%)$.

ISerious indirectness-only one study of 10 participants with type 1 diabetes mellitus was available for analysis; serious imprecision-95\% confidence interval (-0.38\% to $0.42 \%,-27.7$ to $-18.9 \mathrm{mmol} / \mathrm{mol}$ ) overlaps the MID for $\mathrm{HbA} 1 \mathrm{C}(0.3 \%)$, including both clinically important benefit ( $\leq-0.3 \%)$ and harm ( $\geq 0.3 \%)$.

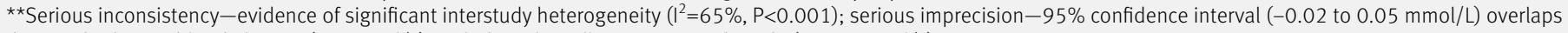
the MID for fasting blood glucose $(0.5 \mathrm{mmol} / \mathrm{L})$, including clinically unimportant benefit $(\geq-0.5 \mathrm{mmol} / \mathrm{L})$.

††Serious inconsistency-evidence of significant intersudy heterogeneity $\left(\mathrm{I}^{2}=71 \%, \mathrm{P}<0.001\right)$; serious imprecision-95\% confidence interval $(-0.00$ to $0.15 \mathrm{mmol} / \mathrm{L})$ overlaps the MID for fasting blood glucose $(0.5 \mathrm{mmol} / \mathrm{L})$, including clinically unimportant benefit $(\geq-0.5 \mathrm{mmol} / \mathrm{L})$.

$\ddagger \neq$ No serious inconsistency-removal of the 2012 study by Tate and colleagues ${ }^{148}$ explained most of the heterogeneity $\left(\mathrm{I}^{2}=32 \%, \mathrm{P}=0.23\right)$, without changing the direction or

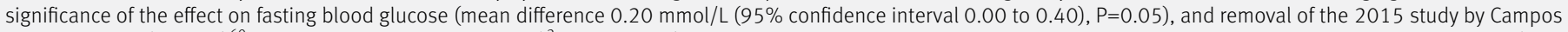

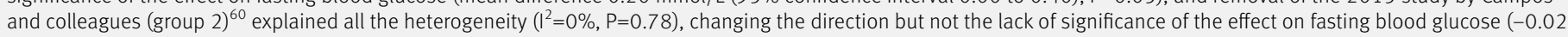
$\mathrm{mmol} / \mathrm{L}$ (-0.11 to 0.07), $\mathrm{P}=0.63)$; serious imprecision-95\% confidence interval ( -0.07 to $0.10 \mathrm{mmol} / \mathrm{L}$ ) overlaps the $\mathrm{MID}$ for fasting blood glucose (0.5 mmol/L), including clinically unimportant benefit ( $\geq-0.5 \mathrm{mmol} / \mathrm{L})$.

$\S \S S$ erious imprecision-95\% confidence interval ( -0.07 to $0.04 \mathrm{mmol} / \mathrm{L}$ ) overlaps the MID for fasting blood glucose (0.5 mmol/L), including clinically unimportant benefit ( $\geq-0.5 \mathrm{mmol} / \mathrm{L})$.

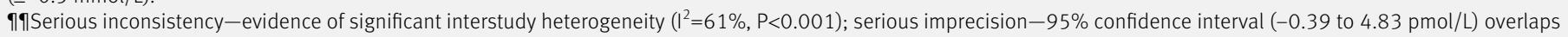
the MID for fasting blood insulin (10 pmol/L), including clinically unimportant benefit $(\geq-10 \mathrm{pmol} / \mathrm{L})$.

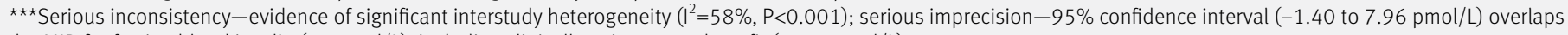
the MID for fasting blood insulin (10 pmol/L), including clinically unimportant benefit $(\geq-10 \mathrm{pmol} / \mathrm{L})$.

t††Serious inconsistency-although the evidence of significant interstudy heterogeneity $\left(I^{2}=79 \%, P<0.01\right)$ was explained by the removal of the 2015 study by Campos and colleagues (group 2$)^{60}\left(I^{2}=1 \%, P=0.31\right)$, the conclusion changed for the significance (from non-significant to significant) and magnitude (from smaller to larger) of the effect

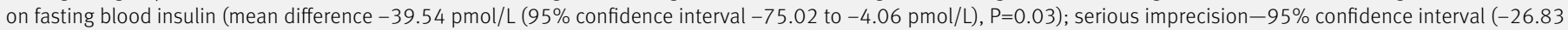
to $22.83 \mathrm{pmol} / \mathrm{L})$ overlaps the MID for fasting blood insulin (10 pmol/L), including both clinically important benefit ( $<10 \mathrm{pmol} / \mathrm{L})$ and harm ( $>10 \mathrm{pmol} / \mathrm{L})$. Only three studies involving 33 participants were available for analysis.

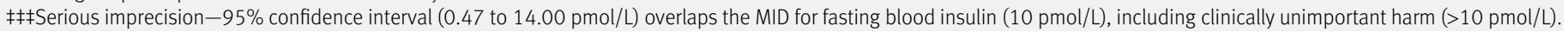

significant $(\mathrm{P}=0.04)$, visual inspection of funnel plots and the Egger test did not show evidence of publication bias for the effect of food sources of fructose containing sugars on fasting blood glucose in substitution studies. Adjustment for funnel plot asymmetry by the Duval and Tweedie method also did not alter the results.

\section{GRADE assessment}

Table 2 shows a summary of the overall quality of evidence assessment for the effect of total fructose- containing sugars independent of food source on the outcome measures of glycaemic control. The certainty in the evidence was variable for HbA1c (low, low, low, and low quality), fasting blood glucose (low, low, moderate, and moderate), and fasting blood insulin (low, low, low, and moderate) across substitution, addition, subtraction, and ad libitum studies, respectively. Evidence for HbA1c was downgraded for inconsistency in substitution and addition studies; for indirectness in subtraction and ad libitum studies; and for imprecision 
in substitution, addition, subtraction, and ad libitum studies. Evidence for fasting blood glucose was downgraded for inconsistency in substitution and addition studies; and for imprecision in substitution, addition, subtraction, and ad libitum studies. Similarly, evidence for fasting blood insulin was downgraded for inconsistency in the substitution, addition, and subtraction studies; and for imprecision in substitution, addition, subtraction, and ad libitum studies.

\section{Discussion}

Our systematic review and meta-analysis of 155 studies including 5086 participants with and without diabetes showed variable effects of food sources of fructose-containing sugars on three outcome measures of glycaemic control at median doses ranging from $12.2 \%$ to $23 \%$ of total energy intake over median follow-up durations of 4.5-12 weeks.

Four types of study designs were identified on the basis of energy control. In substitution studies, total food sources of fructose-containing sugars in energy matched comparisons with other macronutrients (mainly refined starches) showed a beneficial effect on HbA1c with no effects on fasting blood glucose or insulin, while individual food sources showed decreasing (fruit juice), null (fruit, SSBs, baked goods, added sweeteners), or increasing (sweetened milk, mixed sources) effects on fasting blood insulin. In addition studies, total food sources of fructosecontaining sugars supplementing diets with excess energy compared to the same diet alone without the excess energy showed a harmful effect on fasting blood insulin without affecting HbA1c or fasting blood glucose, while individual food sources showed harmful effects on both fasting blood glucose (SSBs and fruit juice) and insulin (SSBs, mixed sources). In the ad libitum studies, total food sources of fructose-containing sugars freely replacing other macronutrients showed a harmful effect on fasting blood insulin (for which the effect was derived exclusively from mixed food sources inclusive of SSBs) without affecting $\mathrm{HbA} 1 \mathrm{c}$ or fasting blood glucose. No effect of food sources of fructose-containing sugars was observed in subtraction studies.

\section{Sources of heterogeneity}

Methodological and clinical sources of heterogeneity had an influence on our results. Sensitivity analyses showed evidence of instability in the significance of our pooled estimates. Removal of any one of six studies ${ }^{38} 4672105114123$ changed the estimates from non-significant to significant for fasting blood glucose in the addition studies, while the removal of a 2000 study by Raben and Astrup $(C)^{124}$ changed the estimates from significant to non-significant for fasting blood insulin in the ad libitum studies. None of the studies explained any of the heterogeneity. Removal of the study by Campos and colleagues (group 2), ${ }^{60}$ however, did explain the heterogeneity and as well as change the significance of the effect. This sensitivity analysis revealed a consistent beneficial effect of reducing excess calories from fructose-containing sugars on fasting blood insulin in subtraction studies. The reason for the strong influence of this study is unclear. As the Campos study ${ }^{60}$ was small $(n=15)$ and received most of the weight in the analysis $(>50 \%)$, its true within-study variances could have been seriously underestimated, leading to an important outlier effect on the pooled estimate for fasting blood insulin. ${ }^{153}$

Subgroup analyses also showed evidence of effect modification under certain conditions. Greater improvements in fasting blood glucose were observed in participants with higher baseline fasting glucose in substitution and addition studies, suggesting a regression to the mean. These effects accorded with the observed subgroup modification by underlying disease status in addition studies, showing a greater beneficial effect on fasting blood glucose in patients with diabetes. A significant subgroup effect by level of feeding control and age were also observed in addition studies where fasting blood glucose was significantly reduced when dietary advice was the method of feeding control or the age of participants was 18 years or younger, but only one study was available for each of these analyses and neither analysis explained the substantial heterogeneity. The relevance of the subgroup analysis for feeding control was also brought into question when we found an opposite result for fasting blood insulin in substitution studies. The dose-response analyses showed a significant effect modification by dose, whereby HbA1c (continuous dose threshold analyses) and fasting blood glucose (categorical analyses) were lower at doses of up to 10\% energy in substitution studies, suggesting that intake meeting current recommendations to consume no more than $10 \%$ of energy from free or added sugars 2233 might have advantages. No further advantages were seen at the other public health thresholds of $5 \%$ free sugars $^{2223}$ and $25 \%$ added sugars. ${ }^{34}$

\section{Results in the context of other studies}

Our findings agree with two other systematic reviews and meta-analyses of controlled intervention studies, which showed a beneficial effect of the isocaloric substitution of fructose for other carbohydrates on glycated blood proteins in participants with diabetes (equivalent to about $0.53 \%$ reduction in $\mathrm{HbA} 1 \mathrm{c})^{13}$ and without diabetes (fructose intake $<90 \mathrm{~g} / \mathrm{day}$ significantly improved HbA1c, dependent on dose, study duration, and severity of dysglycaemia). ${ }^{154}$ The modest decrease of $-0.22 \%$ in HbA1c from our analysis did not exceed the clinically meaningful threshold of $0.3 \%$ proposed by the US Food and Drug administration for the development of new drugs for diabetes as observed in the previous meta-analysis. ${ }^{32}$ However, our findings suggest that food sources of fructose-containing sugars might have modest benefits for long term glycaemic control when they replace other macronutrients on a calorie-for-calorie basis. On the other hand, our results suggest that food sources of fructose-containing sugars providing excess energy 
to the diet could raise fasting blood insulin, according with the findings from our previous systematic reviews and meta-analyses that fructose providing excess energy increases insulin resistance. ${ }^{155}$

Our data also agree with evidence from prospective cohort studies of the relation of fructose-containing sugars with diabetes risk. Although we failed to observe an adverse association of total fructosecontaining sugars independent of food source with incident diabetes in an earlier systematic review and meta-analysis of the available prospective cohort studies, ${ }^{156}$ differential associations have been shown for different food sources of sugars. Systematic reviews and meta-analyses of prospective cohort studies have shown an adverse association with $\mathrm{SSBs}^{16}{ }^{17}$ but a protective association with fruit, ${ }^{18}{ }^{19}$ associations which are consistent with our findings of a harmful effect of SSBs on fasting blood glucose and insulin in addition studies and beneficial effect of fruit on $\mathrm{HbA1c}$ in substitution studies.

\section{Potential mechanisms}

Several proposed mechanisms could explain the observed beneficial effect of food sources of fructosecontaining sugars on $\mathrm{HbA1c}$ when substituted for other calories in the diet. Fructose has a relatively low glycaemic index (GI) of 16, compared with reference carbohydrates such as starch with a GI of 100. ${ }^{157}$ Most of the comparators used in substitution studies were in the form of starch, so replacement of these high GI carbohydrates with fructose could have reduced the overall GI of the diet, leading to long term glycaemic improvement ${ }^{158}$ through alleviation of $\beta$ cell stress. ${ }^{159} 160$ Evidence also suggests that high GI diets are associated with reliable clinical markers of insulin resistance, such as higher triglycerides and lower high density lipoprotein cholesterol. ${ }^{161} 162$

The low GI of fruit could explain why it was the main food source driving a significant improvement in HbA1c in substitution studies, especially when compared with intermediate GI food sources such as SSBs or sweets, which provide calories from sugars in the absence of any nutritional value. The higher fibre content of fruit could contribute to lower postprandial glycaemic excursions. Particularly, viscous gels formed by the pectin in fruit could delay gastric emptying and slow down the release of sugars. ${ }^{163}$ A secondary analysis of a randomised controlled trial of the effect of a six month, low GI intervention showed that low GI fruit intake was the strongest predictor of $\mathrm{HbA} 1 \mathrm{c}$ reduction in people with type 2 diabetes. ${ }^{164}$ Whether low GI food sources of fructose-containing sugars would show similar effects to those of other low GI carbohydrate foods (including legumes or some whole grains) remains unknown, owing to a lack of studies using high quality carbohydrate comparators.

While a low GI mechanism could have contributed to the observed decrease in $\mathrm{HbA} 1 \mathrm{c}$ in the substitution studies), especially as it relates to fruit, it did not extend to improvements in fasting blood glucose and insulin. Although the summary effect estimates for both outcomes tended to be in the direction of benefit (with the possibility of additional studies providing sufficient power to confirm any beneficial effects), a mechanism that targets postprandial excursions in glucose and insulin would not necessarily be expected to lead to meaningful improvements in these fasting measurements, which are determined more by changes in insulin sensitivity. ${ }^{158}$

Analternativemechanismaccounting for theobserved beneficial effects of food sources of fructose-containing sugars on HbA1c in substitution studies relates to a socalled "catalytic" effect of fructose, whereby fructose metabolites have regulatory actions on glucokinase and hepatic glucose uptake. Evidence indicates that fructose, especially at small doses of up to $10 \mathrm{~g} / \mathrm{meal}$ (a level obtainable from fruit), could improve glycaemia by the ability of fructose-1-P to up regulate glucokinase activity through the glucokinase regulatory protein, resulting in decreased hepatic glucose production ${ }^{165}$ and increased glycogen synthesis. ${ }^{166}$ The relevance of this mechanism is unclear. It has not been reliably shown ${ }^{167} 168$ under different experimental conditions, and would be expected to have disproportionally greater effect on fasting blood glucose and insulin than HbA1c, the opposite of what we found in the present study. How dietary fructose interacts with glucose at the level of hepatic glucose homeostasis remains largely underexplored.

The increase in insulin in the absence of a harmful effect on HBA1c or fasting blood glucose with sweetened low fat milk in the substitution studies could relate to an isolated insulinotropic effect of dairy proteins. The ability of protein, especially dairy proteins, co-ingested with carbohydrate to stimulate glucose stimulated insulin secretion has been well described. ${ }^{169-171}$ This isolated finding does not necessarily imply harm, because fasting glucose was not increased and sweetened and unsweetened low fat dairy, especially in the form of yogurt, is associated with decreased risk of weight gain and diabetes incidence. ${ }^{172}$

By contrast, the observed harmful effects of food sources of fructose-containing sugars on glycaemic control in addition studies seem to be largely driven by the energy contribution of the sugars. Fructose-containing sugars supplementing diets with excess calories could promote ectopic weight gain, contributing to downstream insulin resistance and impaired glycaemic control. Related effects have been reported in systematic reviews and metaanalyses of controlled intervention studies of fructose overfeeding for body weight, ${ }^{173}$ blood pressure, ${ }^{174}$ uric acid levels, ${ }^{175}$ markers of non-alcoholic fatty liver disease, ${ }^{176}$ and postprandial triglycerides. ${ }^{177}$ Although fructose has been proposed to increase de novo lipogenesis more than other carbohydrates (owing to fructose's ability to enter glycolysis as an unregulated substrate), leading to weight gain and its downstream cardiometabolic disturbances, this mechanism has been shown to be a minor pathway for fructose disposal. ${ }^{178}$ The mechanism is also not unique to fructose-containing sugars, and weight 
gain with metabolic disturbances would be expected for the overconsumption of food sources of other dietary macronutrients. ${ }^{179}$

The lack of a protective effect of interventions to reduce excess energy from food sources of fructosecontaining sugars in subtraction studies is unclear. It could represent compensation, in which the decrease in energy from food sources of these sugars are compensated by replacement with energy from other food sources or spontaneous changes in physical activity that decrease energy expenditure, preventing weight loss and its downstream metabolic benefits. Compensation might have been more apparent in these studies because they had the longest median followup (12 weeks), and might explain why longer term subtraction studies (with median follow-up of roughly one year) designed to displace excess energy from SSBs have only shown a weight loss benefit in specific subgroups of overweight or obese individuals. ${ }^{180}$ The instability in the significance of the pooled effect estimates might have also had a role. Removal of the Campos study (group 2$)^{60}$ explained the heterogeneity showing significant beneficial effects on fasting insulin, suggesting that this study might have masked a true benefit of interventions to reduce fructosecontaining sugars.

\section{Implications}

As dietary guidelines shift from a focus on individual nutrients towards a focus on foods and dietary patterns, our findings might have implications for guiding recommendations on important food sources of fructose-containing sugars in the prevention and management of diabetes. As various food sources of these sugars tended to show improvements in HbA1c, consumption of foods such as fruit, yogurt, and whole grain cereals to replace foods high in refined starches within the recommendation to consume no more than $10 \%$ of energy from free sugars ${ }^{22}$ might be an effective strategy to improve glycaemic control, especially in people with diabetes. As SSBs tended to impair fasting blood glucose and insulin when adding excess energy to the diet, public health strategies to reduce consumption of SSBs could be useful, especially as they provide empty calories in absence of any nutritional value. While these findings highlight the role of food sources of fructose-containing sugars on glycaemic control, other important cardiometabolic parameters should also be considered in future syntheses.

\section{Strengths and limitations}

Our systematic review and meta-analysis has several strengths. Firstly, we did a comprehensive and reproducible search and selection process of the literature examining the effect of food sources of fructose-containing sugars on glycaemic control. Secondly, collation and synthesis of all the available evidence from a large body (155 studies, $\mathrm{n}=5086$ ) of controlled intervention studies was performed, providing maximum protection against bias (noting that results did not differ between randomised and non-randomised studies). Thirdly, we included an assessment of overall quality of evidence using the GRADE assessment approach.

Several of our analyses presented limitations. Firstly, despite the inclusion of many studies, a limited number of studies used particular food sources. For example, no comparison included sweetened breakfast cereals or yogurt, and only one study comparison was available for sweetened chocolate and two study comparisons for sweetened low fat milk for any of the analyses. Many analyses also had only one or two study comparisons available for inclusion: baked goods, sweets, and desserts for HbA1c in substitution and addition studies (one study); fruit juice for fasting blood glucose and insulin in substitution studies (one); mixed sources for fasting blood glucose and insulin in addition studies (one); SSBs for HbA1c in substitution studies (two); and fruit juice for fasting blood glucose in addition studies (two). As a result, we elected only to do GRADE assessments for total food sources. Secondly, substantial unexplained heterogeneity was present in all analyses for the substitution studies, as well as the addition studies for $\mathrm{HbA} 1 \mathrm{c}$, fasting blood glucose, and fasting blood insulin. Although we also saw substantial heterogeneity in the subtraction studies for $\mathrm{HbA1c}$, fasting blood glucose, and insulin, and ad libitum studies for $\mathrm{HbA} 1 \mathrm{c}$, the removal of individual studies during sensitivity analyses explained this heterogeneity, and so we did not downgrade for inconsistency.

Thirdly, serious indirectness was present in some analyses, because only one trial of 240 overweight and obese women was available in the HbA1c subtraction analysis, and similarly, one trial of 10 patients with diabetes was available in the HbA1c ad libitum analysis. Although the small sample sizes of included studies (median ranging from 15 participants in subtraction studies to 39 participants in ad libitum studies) are another potential source of indirectness, we did not downgrade the evidence for indirectness owing to the large number of included studies, representing a diverse range of study conditions and metabolic phenotypes across many participants. We also did not downgrade for indirectness because of the relatively short duration of follow-up (median 4.5-12 weeks), and we believed that it was sufficient to assess the question of harm (a decision shared with an earlier WHO commissioned review of the evidence for sugars and body weight). ${ }^{181}$ Finally, we saw evidence of serious imprecision in all of the analyses. As the 95\% confidence intervals crossed the minimally important differences for HbA1c, fasting blood glucose, and fasting blood insulin, these analyses were downgraded for serious imprecision. Weighing the strengths and limitations, we graded the quality in the evidence using GRADE as low for HbA1c, low to moderate for fasting blood glucose, and low to moderate for fasting blood insulin across the four study designs based on energy control. 


\section{Conclusion}

The effects of food sources of fructose-containing sugars on glycaemic control appear to be both energy and food source dependent. Food sources of fructosecontaining sugars, especially fruit, substituted for equal amounts of calories from other macronutrient sources (mainly refined starches) led to improvements in HbA1c without adversely affecting fasting blood glucose or insulin. However, when several food sources of fructose-containing sugars added excess energy to the diet, especially SSBs, significant increases in fasting blood glucose and insulin were observed. The same result was also seen for mixed food sources (inclusive of SSBs) of fructose-containing sugars freely replacing other macronutrients on fasting blood insulin without a harmful effect on HbA1c or fasting blood glucose. The anticipated benefit of interventions to reduce the excess energy from sugars, however, was not seen reliably, suggesting that compensatory behaviours might be an important consideration. The lack of any harm and even advantages were most pronounced in those individuals with higher HbA1c and fasting blood glucose at baseline or who had diabetes.

Although our findings suggest that common food sources of fructose-containing sugars do not have harmful effects on glycaemic control in energy matched replacement of other less sugary foods, our GRADE assessment suggests that more research is likely to have an important influence on many of our estimates. More large, high quality studies using a greater variety of food sources of fructose-containing sugars are required to assess the durability of these effects and understand whether certain food sources with an apparent signal for benefit, such as fruit, might even have advantages for glycaemic control under free living conditions over the longer term (six months or longer). Meanwhile, policy and guidelines makers should consider the influence of energy control and food source in the development recommendations to reduce sugars for the prevention and management of diabetes.

\section{AUTHOR AFFILIATIONS}

${ }^{1}$ Toronto 3D (Diet, Digestive Tract, and Disease) Knowledge Synthesis and Clinical Trials Unit, Clinical Nutrition and Risk Factor Modification Centre, St Michael's Hospital, 61 Queen Street East, Toronto, ON, M5C 2T2, Canada

${ }^{2}$ Department of Nutritional Sciences, Faculty of Medicine, University of Toronto, Toronto, ON, Canada

${ }^{3}$ Undergraduate Medical Education, Cumming School of Medicine, University of Calgary, Calgary, AB, Canada

${ }^{4}$ Department of Radiation Oncology, Faculty of Medicine, University of Toronto, Toronto, ON, Canada

5Undergraduate Medical Education, School of Medicine, Queen's University, Kingston, ON, Canada

${ }^{6}$ Department of Health Research Methods, Evidence, and Impact, McMaster University, Hamilton, ON, Canada

${ }^{7}$ Li Ka Shing Knowledge Institute, St Michael's Hospital, Toronto, ON, Canada

${ }^{8}$ Division of Endocrinology and Metabolism, Department of Medicine, St Michael's Hospital, Toronto, ON, Canada

${ }^{9}$ College of Pharmacy and Nutrition, University of Saskatchewan, Saskatoon, SK, Canada
We thank Zujaja-Tul-Noor for her help in creating some of the figures. Aspects of this work were presented at the 34th International Symposium on Diabetes and Nutrition, Diabetes and Nutrition Study Group of the European Association of the Study of Diabetes, in Prague, Czech Republic (29 June to 1 July 2016)

Contributors: VLC, SBM, and JLS had full access to all of the data in the study and take responsibility for the integrity of the data and the accuracy of the data analysis. VLC, JLS, and DJAJ were responsible for the study concept and design. VLC, EV, SBM, AIC, VH, LAL, TMSW, TAK, DJAJ, and JLS were responsible for the acquisition, analysis, and interpretation of data. VLC drafted the manuscript. All the authors contributed to the critical revision of the manuscript for important intellectual content. VLC and SBM conducted the statistical analysis. JLS and DJAI supervised the study. JLS was the study guarantor. The corresponding author attests that all listed authors meet authorship criteria and that no others meeting the criteria have been omitted.

Funding: This work was funded by Diabetes Canada (grant CS-515-4771-JS). The Diet, Digestive tract, and Disease (3D) Centre, funded through the Canada Foundation for Innovation and the Ministry of Research and Innovation's Ontario Research Fund, provided the infrastructure for the conduct of this work. DJAJ was funded by the Government of Canada through the Canada Research Chair Endowment. JLS was funded by the PSI Graham Farquharson Knowledge Translation Fellowship, Diabetes Canada Clinician Scientist award, Canadian Institutes of Health Research's Institute of Nutrition, Metabolism, and Diabetes-Canadian Nutrition Society (CIHR INMD-CNS) New Investigator Partnership Prize, and Banting and Best Diabetes Centre Sun Life Financial New Investigator Award. None of the sponsors had a role in any aspect of the present study, including design and conduct of the study; collection, management, analysis, and interpretation of the data; and preparation, review, approval of the manuscript or decision to publish.

Competing interests: All authors have completed the ICMJE uniform disclosure form at www.icmje.org/coi disclosure.pdf and declare: support from Diabetes Canada and the Diet, Digestive tract, and Disease Centre through the Canada Foundation for Innovation and the Ministry of Research and Innovation's Ontario Research Fund for the submitted work. TMSW is a part owner and president of Glycemic Index Laboratories, Toronto, Canada, and has authored several diet books on the glycaemic index for which he has received royalties from Phillipa Sandall Publishing Services and CABI Publishers; and has received consultant fees, honorariums, travel funding, or research support from or served on the scientific advisory board for Canadian Institutes of Health Research, Canadian Diabetes Association, Dairy Farmers of Canada, McCain Foods, Temasek Polytechnic, Northwestern University, Royal Society of London, Glycemic Index Symbol programme, CreaNutrition AG, McMaster University, Canadian Society for Nutritional Sciences, National Sports and Conditioning Association, Faculty of Public Health and Nutrition-Autonomous University of

Nuevo Leon, and Diabetes and Nutrition Study Group of the European Association for the Study of Diabetes. VV has a Canadian (2410 556) and American $(7,326.404)$ patent on the medical use of viscous fibre blend for reducing blood glucose for treatment of diabetes, increasing insulin sensitivity, and reduction in systolic blood pressure and blood lipids issued. CWCK has received grants or research support from the Advanced Food Materials Network, Agriculture and Agri-Foods Canada, Almond Board of California, American Pistachio Growers, Barilla, Calorie Control Council, Canadian Institutes of Health Research, Canola Council of Canada, International Nut and Dried Fruit Council, International Tree Nut Council Research and Education Foundation, Loblaw Brands, Pulse Canada, Saskatchewan Pulse Growers and Unilever; has received in-kind research support from the Almond Board of California, American Peanut Council, Barilla, California Walnut Commission, Kellogg Canada, Loblaw Companies, Quaker (PepsiCo), Primo, Unico, Unilever, WhiteWave Foods; has received travel support or honorariums from the American Peanut Council, American Pistachio Growers, Barilla, California Walnut Commission, Canola Council of Canada, General Mills, International Nut and Dried Fruit Council, International Pasta Organization, Loblaw Brands Ltd, Nutrition Foundation of Italy, Oldways Preservation Trust, Paramount Farms, Peanut Institute, Pulse Canada, Sabra Dipping, Saskatchewan Pulse Growers, Sun-Maid, Tate \& Lyle, Unilever and White Wave Foods; has served on the scientific advisory board for the International Tree Nut Council, International Pasta Organization, McCormick Science Institute, Oldways Preservation Trust, Paramount Farms and Pulse Canada; is a member of the International Carbohydrate Quality Consortium, executive board member of the Diabetes and Nutrition Study Group of the European Association for the Study of Diabetes; is on the Clinical Practice Guidelines Expert Committee for Nutrition Therapy of the 
European Association for the Study of Diabetes; and is a director of the Toronto 3D Knowledge Synthesis and Clinical Trials Foundation. RJdS has received research support from the Canadian Foundation for Dietetic Research, Population Health Research Institute, and Hamilton Health Sciences Corporation; travel and consultant fees from the World Health Organization; consultant fees from Canadian Institutes of Health Research's Institute of Nutrition, Metabolism, and Diabetes and Health Canada; and a speaker's honorarium from McMaster Children's Hospital. DJAJ has received research grants from Saskatchewan Pulse Growers, the Agricultural Bioproducts Innovation Programme through the Pulse Research Network, Advanced Foods and Material Network, Loblaw Companies, Unilever, Barilla, Almond Board of California, Agriculture and Agri-food Canada, Pulse Canada, Kellogg's Company (Canada), Quaker Oats (Canada), Procter and Gamble Technical Centre, Bayer Consumer Care (Springfield, NJ, USA), Pepsi/Quaker, International Nut and Dried Fruit, Soy Foods Association of North America, Coca-Cola Company (investigator initiated, unrestricted grant), Solae, Haine Celestial, Sanitarium Company, Orafti, International Tree Nut Council Nutrition Research and Education Foundation, Peanut Institute, Soy Nutrition Institute, Canola and Flax Councils of Canada, Calorie Control Council, Canadian Institutes of Health Research, Canada Foundation for Innovation, and Ontario Research Fund; has received in-kind supplies for trials as a research support from the Almond board of California, Walnut Council of California, American Peanut Council, Barilla, Unilever, Unico, Primo, Loblaw Companies, Quaker (PepsiCo), Pristine Gourmet, Bunge, Kellogg Canada, and WhiteWave Foods; has been on the speaker's panel, served on the scientific advisory board or received trave support or honorariums from the Almond Board of California, Canadian Agriculture Policy Institute, Loblaw Companies, Griffin Hospital (for the development of the NuVal scoring system), Coca-Cola Company, EPICURE, Danone, Diet Quality Photo Navigation, Better Therapeutics (FareWell), Verywell, True Health Initiative, Institute of Food Technologists, Soy Nutrition Institute, Herbalife Nutrition Institute, Saskatchewan Pulse Growers, Sanitarium Company, Orafti, Almond Board of California, American Peanut Council, International Tree Nut Council Nutrition Research and Education Foundation, Peanut Institute, Herbalife International, Pacific Health Laboratories, Nutritional Fundamentals for Health, Barilla, Metagenics, Bayer Consumer Care, Unilever Canada and Netherlands, Solae, Kellogg, Quaker Oats, Procter and Gamble, Abbott Laboratories, Dean Foods, California Strawberry Commission, Haine Celestial, PepsiCo, Alpro Foundation, Pioneer Hi-Bred International, DuPont Nutrition and Health, Spherix Consulting and WhiteWave Foods, Advanced Foods and Material Network, Canola and Flax Councils of Canada, Agri-Culture and Agri-Food Canada, Canadian Agri-Food Policy Institute, Pulse Canada, Saskatchewan Pulse Growers, Soy Foods Association of North America, Nutrition Foundation of Italy, Nutra-Source Diagnostics, McDougall Programme, Toronto Knowledge Translation Group (St Michael's Hospital), Canadian College of Naturopathic Medicine, The Hospital for Sick Children, Canadian Nutrition Society, American Society of Nutrition, Arizona State University, Paolo Sorbini Foundation, and the Institute of Nutrition, Metabolism, and Diabetes; has received an honorarium from the US Department of Agriculture to present the 2013 W O Atwater Memorial Lecture and the 2013 Award for Excellence in Research from the International Nut and Dried Fruit Council; has received funding and travel support from the Canadian Society of Endocrinology and Metabolism to produce mini cases for the Canadian Diabetes Association; and is a member of the International Carbohydrate Quality Consortium. DJAJ's wife, Alexandra L Jenkins, is a director and partner of Glycemic Index Laboratories, and his sister, Caroline Brydson, received funding through a grant from the St Michael's Hospital Foundation to develop a cookbook for one of his studies. JLS has received research support from the Canadian Institutes of Health Research, Diabetes Canada, PSI Foundation, Banting and Best Diabetes Centre, American Society for Nutrition, INC International Nut and Dried Fruit Council Foundation, National Dried Fruit Trade Association, the Tate and Lyle Nutritional Research Fund at the University of Toronto, the Glycemic Control and Cardiovascular Disease in Type 2 Diabetes Fund at the University of Toronto (a fund established by the Alberta Pulse Growers), and the Nutrition Trialists Fund at the University of Toronto (a fund established by the Calorie Control Council); has received food donations to support randomised controlled trials from the Almond Board of California, California Walnut Commission, American Peanut Council, Barilla, Unilever, Unico/Primo, Loblaw Companies, Quaker (PepsiCo), Kellogg Canada, and WhiteWave Foods; has received speaker fees or honorariums from Diabetes Canada, Canadian Nutrition Society, Mott's, Dairy Farmers o Canada, Alberta Milk, FoodMinds, Memac Ogilvy \& Mather, PepsiCo,
The Ginger Network, International Sweeteners Association, Nestlé, Pulse Canada, Canadian Society for Endocrinology and Metabolism, GI Foundation, Barilla Centre for Food and Nutrition, Abbott, Biofortis, California Walnut Commission, American Society for Nutrition, Loma Linda University, Dietitians of Canada, European Food Safety Authority, and Physicians Committee for Responsible Medicine; has ad hoc consulting arrangements with Winston and Strawn, Perkins Coie, and Tate and Lyle, and Wirtschaftliche Vereinigung Zucker eV; is a member of the European Fruit Juice Association's scientific expert panel; is on the clinical practice guidelines expert committees of Diabetes Canada, European Association for the Study of Diabetes, Canadian Cardiovascular Society, and Obesity Canada; serves as an unpaid scientific adviser for the Food, Nutrition, and Safety Programme and the technical committee on carbohydrates of the International Life Science Institute North America; and is a member of the International Carbohydrate Quality Consortium, executive board member of the Diabetes and Nutrition Study Group of the European Association for the Study of Diabetes, and director of the Toronto 3D Knowledge Synthesis and Clinical Studies foundation. JLS's wife is an employee of Unilever Canada. VLC, EV, SBM, AIC, TAK, VH, and LAL declare no competing interests. There are no products in development or marketed products to declare.

Ethical approval: Not required.

Data sharing: No additional data are available.

The lead author affirms that this manuscript is an honest, accurate, and transparent account of the study being reported; that no important aspects of the study have been omitted; and that any discrepancies from the study as planned (and, if relevant, registered) have been explained.

This is an Open Access article distributed in accordance with the Creative Commons Attribution Non Commercial (CC BY-NC 4.0) license, which permits others to distribute, remix, adapt, build upon this work non-commercially, and license their derivative works on different terms, provided the original work is properly cited and the use is noncommercial. See: http://creativecommons.org/licenses/by-nc/4.0/.

1 Bray GA, Popkin BM. Dietary sugar and body weight: have we reached a crisis in the epidemic of obesity and diabetes?: health be damned! Pour on the sugar. Diabetes Care 2014;37:950-6. $10.2337 / \mathrm{dc} 13-2085$

2 Kahn R, Sievenpiper JL. Dietary sugar and body weight: have we reached a crisis in the epidemic of obesity and diabetes?: we have, but the pox on sugar is overwrought and overworked. Diabetes Care 2014;37:957-62. 10.2337/dc13-2506

3 Gross LS, Li L, Ford ES, Liu S. Increased consumption of refined carbohydrates and the epidemic of type 2 diabetes in the United States: an ecologic assessment. Am J Clin Nutr 2004;79:774-9. doi:10.1093/ajcn/79.5.774

4 Goran MI, Ulijaszek SI, Ventura EE. High fructose corn syrup and diabetes prevalence: a global perspective. Glob Public Health 2013;8:55-64. doi:10.1080/17441692.2012. 736257

5 Bantle JP, Laine DC, Thomas JW. Metabolic effects of dietary fructose and sucrose in types I and II diabetic subjects. JAMA 1986;256:3241-6. doi:10.1001/ jama.1986.03380230065027

6 Lustig RH. Fructose: it's “alcohol without the buzz”. Adv Nutr 2013:4:226-35. doi:10.3945/an.112.002998

7 Huang BW, Chiang MT, Yao HT, Chiang W. The effect of high-fat and high-fructose diets on glucose tolerance and plasma lipid and leptin levels in rats. Diabetes Obes Metab 2004;6:120-6. doi:10.1111/j.1462-8902.2004.00323.x

8 de Moura RF, Ribeiro C, de Oliveira JA, Stevanato E, de Mello MA. Metabolic syndrome signs in Wistar rats submitted to different high-fructose ingestion protocols. Br / Nutr 2009;101:1178-84. doi:10.1017/S0007114508066774

9 Hwang IS, Ho H, Hoffman BB, Reaven GM. Fructose-induced insulin resistance and hypertension in rats. Hypertension 1987;10:512-6. doi:10.1161/01.HYP.10.5.512

10 Hendler R, Bonde AA. Effects of sucrose on resting metabolic rate, nitrogen balance, leucine turnover and oxidation during weight loss with low calorie diets. Int J Obes 1990;14:927-38.

11 Hendler RG, Walesky M, Sherwin RS. Sucrose substitution in prevention and reversal of the fall in metabolic rate accompanying hypocaloric diets. Am J Med 1986;81:280-4. doi:10.1016/00029343(86)90264-0

12 Yudkin J. Szanto S. Increased levels of plasma insulin and eleven hydroxycorticosteroid induced by sucrose, and their reduction by phenformin. Hormone Metab Res 1972;4:417-20.

13 Cozma Al, Sievenpiper JL, de Souza RJ, et al. Effect of fructose on glycemic control in diabetes: a systematic review and meta-analysis 
of controlled feeding trials. Diabetes Care 2012;35:1611-20. doi:10.2337/dc12-0073

14 White JS. Challenging the fructose hypothesis: new perspectives on fructose consumption and metabolism. Adv Nutr 2013;4:246-56. doi:10.3945/an.112.003137

15 Theytaz F, de Giorgi S, Hodson L, et al. Metabolic fate of fructose ingested with and without glucose in a mixed meal. Nutrients 2014;6:2632-49. doi:10.3390/nu6072632

16 Imamura F, O'Connor L, Ye Z, et al. Consumption of sugar sweetened beverages, artificially sweetened beverages, and fruit juice and incidence of type 2 diabetes: systematic review, meta-analysis, and estimation of population attributable fraction. BMJ 2015;351:h3576. doi:10.1136/bmj.h3576

17 Greenwood DC, Threapleton DE, Evans CE, et al. Association between sugar-sweetened and artificially sweetened soft drinks and type 2 diabetes: systematic review and dose-response meta-analysis of prospective studies. Br J Nutr 2014;112:725-34. doi:10.1017/ S0007114514001329

18 Li S, Miao S, Huang Y, et al. Fruit intake decreases risk of incident type 2 diabetes: an updated meta-analysis. Endocrine 2015;48:454-60. doi:10.1007/s12020-014-0351-6

19 Muraki I, Imamura F, Manson JE, et al. Fruit consumption and risk of type 2 diabetes: results from three prospective longitudinal cohort studies [correction in: BMJ 2013;347:f6935]. BMJ 2013;347:f5001. doi:10.1136/bmj.f5001

20 Manios Y, Moschonis G, Mavrogianni C, et al. Postprandial glucose and insulin levels in type 2 diabetes mellitus patients after consumption of ready-to-eat mixed meals. Eur Nutr 2017;56:1359-67. doi:10.1007/s00394-016-1186-0

21 Sievenpiper JL, Dworatzek PD. Food and dietary patternbased recommendations: an emerging approach to clinical practice guidelines for nutrition therapy in diabetes. Can J Diabetes 2013;37:51-7. doi:10.1016/j.jcjd.2012.11.001

22 Guideline: sugars intake for adults and children. WHO Guidelines approved by the Guidelines Review Committee. Geneva, 2015. https://www.ncbi.nlm.nih.gov/books/NBK285537/pdf/Bookshelf_ NBK285537.pdf

23 Scientific Advisory Committe on Nutrition. Carbohydrates and health. Stationery Office. 2015. https://www.gov.uk/government/ uploads/system/uploads/attachment_data/file/445503/SACN Carbohydrates_and_Health.pdf.

24 Higgins JPT, Green S. Cochrane Handbook for systematic reviews of interventions version 5.1.0 [updated March 2011]. Cochrane Collaboration. https://handbook-5-1.cochrane.org/

25 Moher D, Liberati A, Tetzlaff J, Altman DG, PRISMA Group. Preferred reporting items for systematic reviews and meta-analyses: the PRISMA statement. Int J Surg 2010;8:336-41. doi:10.1016/j. ijsu.2010.02.007

26 Wilczynski NL, Morgan D, Haynes RB, Hedges Team. An overview of the design and methods for retrieving high-quality studies for clinical care. BMC Med Inform Decis Mak 2005;5:20. doi:10.1186/1472-6947-5-20

27 Higgins JP, Altman DG, Gøtzsche PC, et al, Cochrane Bias Methods Group, Cochrane Statistical Methods Group. The Cochrane Collaboration's tool for assessing risk of bias in randomised trials. BMJ 2011;343:d5928. doi:10.1136/bmj.d5928

28 Elbourne DR, Altman DG, Higgins JP, Curtin F, Worthington HV, Vail A. Meta-analyses involving cross-over trials: methodological issues. Int J Epidemiol 2002;31:140-9. doi:10.1093/ije/31.1.140

29 Higgins JP, Thompson SG, Deeks JJ, Altman DG. Measuring inconsistency in meta-analyses. BM/ 2003;327:557-60. doi:10.1136/bmj.327.7414.557

30 Borenstein M, Hedges LV, Higgins JP, Rothstein HR. Introduction to meta-analysis. John Wiley \& Sons, 2008.

31 Thompson SG, Higgins JP. How should meta-regression analyses be undertaken and interpreted? Stat Med 2002:21:1559-73. doi:10.1002/sim.1187

32 US Department of Health and Human Services and US Department of Agriculture. 2015-2020 dietary guidelines for Americans. 8th ed. December 2015. https://health.gov/dietaryguidelines/2015/ guidelines/.

33 USDA. Scientific Report of the 2015 Dietary Guidelines Advisory Committee. In: DGAC-USDA, ed. 2015. https://health.gov/ dietaryguidelines/2015-scientific-report/pdfs/scientific-report-ofthe-2015-dietary-guidelines-advisory-committee.pdf.

34 Institute of Medicine. Dietary reference intakes for energy, carbohydrate, fiber, fat, fatty acids, cholesterol, protein, and amino acids. National Academies Press, 2005.

35 Sterne JA, Gavaghan D, Egger M. Publication and related bias in meta-analysis: power of statistical tests and prevalence in the literature. / Clin Epidemiol 2000;53:1119-29. doi:10.1016/S0895-4356(00)00242-0
36 Duval S, Tweedie R. Trim and fill: A simple funnel-plot-based method of testing and adjusting for publication bias in meta-analysis. Biometrics 2000;56:455-63. doi:10.1111/j.0006-341X.2000.00455.x

37 Guyatt G, Oxman AD, Akl EA, et al. GRADE guidelines: 1. IntroductionGRADE evidence profiles and summary of findings tables. / Clin Epidemiol 2011;64:383-94. doi:10.1016/j.jclinepi.2010.04.026

38 Abdel-Sayed A, Binnert C, Lê KA, Bortolotti M, Schneiter P, Tappy L. A high-fructose diet impairs basal and stress-mediated lipid metabolism in healthy male subjects. Br J Nutr 2008;100:393-9. doi:10.1017/S000711450789547X

39 Abdulrhman MM, El-Hefnawy MH, Aly RH, et al. Metabolic effects of honey in type 1 diabetes mellitus: a randomized crossover pilot study. J Med Food 2013;16:66-72. doi:10.1089/jmf.2012.0108

40 Abraira C, Derler J. Large variations of sucrose in constant carbohydrate diets in type II diabetes. Am I Med 1988;84:193-200. doi:10.1016/0002-9343(88)90413-5

41 Aeberli I, Gerber PA, Hochuli M, et al. Low to moderate sugar-sweetened beverage consumption impairs glucose and lipid metabolism and promotes inflammation in healthy young men: a randomized controlled trial. Am J Clin Nutr 2011;94:479-85. doi:10.3945/ajcn.111.013540

42 Aeberli I, Hochuli M, Berneis K. Response to comment on: Aeberli et al. Moderate amounts of fructose consumption impair insulin sensitivity in healthy young men: a randomized controlled trial. Diabetes Care 2013;36:150-156. Diabetes Care 2013;36:e105. doi:10.2337/dc13-0299

43 Agebratt C, Ström E, Romu T, et al. A randomized study of the effects of additional fruit and nuts consumption on hepatic fat content, cardiovascular risk factors and basal metabolic rate. PLOS One 2016;11:e0147149. doi:10.1371/journal.pone.0147149

44 Anderson JW, Story LJ, Zettwoch NC, Gustafson NJ, Jefferson BS. Metabolic effects of fructose supplementation in diabetic individuals. Diabetes Care 1989;12:337-44. doi:10.2337/ diacare.12.5.337

45 Anderson JW, Weiter KM, Christian AL, Ritchey MB, Bays HE. Raisins compared with other snack effects on glycemia and blood pressure: a randomized, controlled trial. Postgrad Med 2014;126:37-43. doi:10.3810/pgm.2014.01.2723

46 Bahrami M, Ataie-Jafari A, Hosseini S, Foruzanfar MH, Rahmani M, Pajouhi M. Effects of natural honey consumption in diabetic patients: an 8-week randomized clinical trial. Int J Food Sci Nutr 2009;60:618-26. doi:10.3109/09637480801990389

47 Banini AE, Boyd LC, Allen JC, Allen HG, Sauls DL. Muscadine grape products intake, diet and blood constituents of non-diabetic and type 2 diabetic subjects. Nutrition 2006;22:1137-45. doi:10.1016/j. nut.2006.08.012

48 Bantle JP, Raatz SK, Thomas W, Georgopoulos A. Effects of dietary fructose on plasma lipids in healthy subjects. Am J Clin Nutr 2000;72:1128-34. doi:10.1093/ajcn/72.5.1128

49 Bantle JP, Swanson JE, Thomas W, Laine DC. Metabolic effects of dietary fructose in diabetic subjects. Diabetes Care 1992:15:1468-76. doi:10.2337/diacare.15.11.1468

50 Bantle JP, Swanson JE, Thomas W, Laine DC. Metabolic effects of dietary sucrose in type II diabetic subjects. Diabetes Care 1993:16:1301-5 doi:10.2337/diacare 16.9.1301

51 Basu A, Du M, Leyva MJ, et al. Blueberries decrease cardiovascular risk factors in obese men and women with metabolic syndrome. J Nutr 2010;140:1582-7. doi:10.3945/jn.110.124701

52 Bays H, Weiter K, Anderson I. A randomized study of raisins versus alternative snacks on glycemic control and other cardiovascular risk factors in patients with type 2 diabetes mellitus. Phys Sportsmed 2015:43:37-43. doi:10.1080/00913847.2015.998410

53 Beck-Nielsen H, Pedersen O, Lindskov HO. Impaired cellular insulin binding and insulin sensitivity induced by high-fructose feeding in normal subjects. Am J Clin Nutr 1980;33:273-8. doi:10.1093/ ajcn/33.2.273

54 Behall KM, Moser PB, Kelsay IL, Prather ES. The effect of kind of carbohydrate in the diet and use of oral contraceptives on metabolism of young women. III. Serum glucose, insulin, and glucagon. Am J Clin Nutr 1980;33:1041-8. doi:10.1093/ ajcn/33.5.1041

55 Black RN, Spence M, McMahon RO, et al. Effect of eucaloric high- and low-sucrose diets with identical macronutrient profile on insulin resistance and vascular risk: a randomized controlled trial. Diabetes 2006;55:3566-72. doi:10.2337/db06-0220

56 Blayo A, Fontevieille S, Rizkalla S, Bruzzo F, Slama G. Effets métaboliques de la consommation quotidienne pendant un an de saccharose ou de fructose par des diabétiques. Med Nutr 1990;26:11-4.

57 Brymora A, Flisiński M, Johnson RJ, Goszka G, Stefańska A, Manitius J. Low-fructose diet lowers blood pressure and inflammation in patients with chronic kidney disease. Nephrol Dial Transplant 2012;27:60812. doi:10.1093/ndt/gfr223 
58 Brynes AE, Mark Edwards C, Ghatei MA, et al. A randomised fourintervention crossover study investigating the effect of carbohydrates on daytime profiles of insulin, glucose, non-esterified fatty acids and triacylglycerols in middle-aged men. Br J Nutr 2003;89:207-18. doi:10.1079/BJN2002769

59 Buysschaert M, Sory R, Mpoy M, Lambert AE. Effect of the addition of simple sugars to mixed meals on the glycemic control of insulin treated diabetic patients. Diabete Metab 1987;13:625-9.

60 Campos V, Despland C, Brandejsky V, et al. Sugar- and artificially sweetened beverages and intrahepatic fat: A randomized controlled trial. Obesity (Silver Spring) 2015;23:2335-9. doi:10.1002/ oby. 21310

61 Chantelau EA, Gösseringer G, Sonnenberg GE, Berger M. Moderate intake of sucrose does not impair metabolic control in pump-treated diabetic out-patients. Diabetologia 1985;28:204-7. doi:10.1007/ BF00282233

62 Christensen AS, Viggers L, Hasselström K, Gregersen S. Effect of fruit restriction on glycemic control in patients with type 2 diabetes--a randomized trial. Nutr 1 2013:12:29. doi:10.1186/1475-2891-12-29

63 Claesson AL, Holm G, Ernersson A, Lindström T, Nystrom FH. Two weeks of overfeeding with candy, but not peanuts, increases insulin levels and body weight. Scand I Clin Lab Invest 2009;69:598-605. doi:10.1080/00365510902912754

64 Colagiuri S, Miller JJ, Edwards RA. Metabolic effects of adding sucrose and aspartame to the diet of subjects with noninsulin-dependent diabetes mellitus. Am J Clin Nutr 1989;50:474-8. doi:10.1093/ ajcn/50.3.474

65 Conceição de Oliveira M, Sichieri R, Sanchez Moura A. Weigh loss associated with a daily intake of three apples or three pears among overweight women. Nutrition 2003;19:253-6. doi:10.1016/S0899-9007(02)00850-X

66 Cooper PL, Wahlqvist ML, Simpson RW. Sucrose versus saccharin as an added sweetener in non-insulin-dependent diabetes: short- and medium-term metabolic effects. Diabet Med 1988;5:67680. doi:10.1111/j.1464-5491.1988.tb01079.x

67 Costa PC, Franco L). [Introduction of sucrose in the diet plan of persons with type 1 diabetes: its influence in the glycemic control] Ara Bras Endocrinol Metabol 2005;49:403-9. doi:10.1590/S000427302005000300012

68 Coulston AM, Hollenbeck CB, Donner CC, Williams R, Chiou YA, Reaven GM. Metabolic effects of added dietary sucrose in individuals with noninsulin-dependent diabetes mellitus (NIDDM). Metabolism 1985;34:962-6. doi:10.1016/0026-0495(85)90146-5

69 Cressey R, Kumsaiyai W, Mangklabruks A. Daily consumption of banana marginally improves blood glucose and lipid profile in hypercholesterolemic subjects and increases serum adiponectin in type 2 diabetic patients. Indian J Exp Biol 2014;52:1173-81

70 Despland C, Walther B, Kast C et al. A randomized-controlled clinical trial of high fructose diets from either Robinia honey or free fructose and glucose in healthy normal weight males. Clin Nutr ESPEN 2017;19:16-22. doi:10.1016/i.clnesp.2017.01.009.

71 Dunnigan MG, Fyfe T, McKiddie MT, Crosbie SM. The effects of isocaloric exchange of dietary starch and sucrose on glucose tolerance, plasma insulin and serum lipids in man. Clin Sci 1970;38:1-9. doi:10.1042/cs0380001

72 Ellis CL, Edirisinghe I, Kappagoda T, Burton-Freeman B. Attenuation of meal-induced inflammatory and thrombotic responses in overweight men and women after 6-week daily strawberry (Fragaria) intake. A randomized placebo-controlled trial. / Atheroscler Thromb 2011;18:318-27. doi:10.5551/jat.6114

73 Emanuele MA, Abraira C, Jellish WS, DeBartolo M. A crossover trial of high and low sucrose-carbohydrate diets in type II diabetics with hypertriglyceridemia. J Am Coll Nutr 1986;5:429-37. doi:10.1080/0 7315724.1986.10720145

74 Enginyurt O, Cakir L, Karatas A, et al. The role of pure honey in the treatment of diabetes mellitus. Biomedical Research (India) 2017;28:3305-12

75 Friedman M, Rosenman RH, Byers SO, Elevitch FR. Effect of low sugar intake upon blood lipids and insulin levels of hyperlipemic subjects. Proc Soc Exp Biol Med 1970;135:785-91. doi:10.3181/00379727 $135-35144$

76 Fry AJ. The effect of a 'sucrose-free' diet on oral glucose tolerance in man. Nutr Metab 1972;14:313-23. doi:10.1159/000175395

77 Grigoresco C, Rizkalla SW, Halfon P, et al. Lack of detectable deleterious effects on metabolic control of daily fructose ingestion for 2 mo in NIDDM patients. Diabetes Care 1988;11:546-50. doi:10.2337/diacare.11.7.546

78 Hallfrisch J, Ellwood KC, Michaelis OE4th, Reiser S, O’Dorisio TM, Prather ES. Effects of dietary fructose on plasma glucose and hormone responses in normal and hyperinsulinemic men. J Nutr 1983;113:1819-26. doi:10.1093/jn/113.9.1819

79 Heden TD, Liu Y, Park YM, Nyhoff LM, Winn NC, Kanaley JA. Moderate amounts of fructose- or glucose-sweetened beverages do not differentially alter metabolic health in male and female adolescents. Am / Clin Nutr 2014:100:796-805. doi:10.3945/ajcn.113.081232

80 Heden TD, Liu Y, Park YM, Winn NC, Kanaley JA. Walking reduces postprandial insulin secretion in obese adolescents consuming a high-fructose or high-glucose diet. J Phys Act Health 2015;12:1153-61. doi:10.1123/jpah.2014-0105

81 Hegde SV, Adhikari P, M N, D'Souza V. Effect of daily supplementation of fruits on oxidative stress indices and glycaemic status in type 2 diabetes mellitus. Complement Ther Clin Pract 2013;19:97-100. doi:10.1016/j.ctcp.2012.12.002

82 Hernández-Cordero S, Barquera S, Rodríguez-Ramírez S, et al. Substituting water for sugar-sweetened beverages reduces circulating triglycerides and the prevalence of metabolic syndrome in obese but not in overweight Mexican women in a randomized controlled trial. J Nutr 2014;144:1742-52. doi:10.3945/jn.114.193490

83 Hollis JH, Houchins JA, Blumberg JB, Mattes RD. Effects of concord grape juice on appetite, diet, body weight, lipid profile, and antioxidant status of adults. J Am Coll Nutr 2009;28:574-82. doi:10.1080/07315724.2009.10719789

84 Huttunen JK, Mäkinen KK, Scheinin A. Turku sugar studies XI. Effects of sucrose, fructose and xylitol diets on glucose, lipid and urate metabolism. Acta Odontol Scand 1976;34:345-51. doi:10.3109/00016357609004646

85 Jellish WS, Emanuele MA, Abraira C. Graded sucrose/ carbohydrate diets in overtly hypertriglyceridemic diabetic patients. Am / Med 1984:77:1015-22. doi:10.1016/0002-9343(84)90181-5

86 Jin R, Welsh JA, Le NA, et al. Dietary fructose reduction improves markers of cardiovascular disease risk in Hispanic-American adolescents with NAFLD. Nutrients 2014:6:3187-201. doi:10.3390/nu6083187

87 Jones JB, Provost M, Keaver L, Breen C, Ludy MJ, Mattes RD. A randomized trial on the effects of flavorings on the health benefits of daily peanut consumption. Am J Clin Nutr 2014;99:490-6. doi:10.3945/ajcn.113.069401

88 Johnston RD, Stephenson MC, Crossland H, et al. No difference between high-fructose and high-glucose diets on liver triacylglycerol or biochemistry in healthy overweight men. Gastroenterology 2013;145:1016-25 e2

89 Kaliora AC, Kokkinos A, Diolintzi A, et al. The effect of minimal dietary changes with raisins in NAFLD patients with non-significant fibrosis: a randomized controlled intervention. Food Funct 2016;7:4533-44 doi:10.1039/C6FO01040G

90 Kanellos PT, Kaliora AC, Tentolouris NK, et al. A pilot, randomized controlled trial to examine the health outcomes of raisin consumption in patients with diabetes. Nutrition 2014;30:358-64. doi:10.1016/j.nut.2013.07.020

91 Kelsay JL, Behall KM, Holden JM, Prather ES. Diets high in glucose or sucrose and young women. Am J Clin Nutr 1974;27:926-36. doi:10.1093/ajcn/27.9.926

92 Koh ET, Ard NF, Mendoza F. Effects of fructose feeding on blood parameters and blood pressure in impaired glucose-tolerant subjects / Am Diet Assoc 1988.88.932-8.

93 Koivisto VA, Yki-Järvinen $\mathrm{H}$. Fructose and insulin sensitivity in patients with type 2 diabetes. J Intern Med 1993;233:145-53. doi:10.1111/j.1365-2796.1993.tb00667x

94 Kolehmainen M, Mykkänen O, Kirjavainen PV, et al. Bilberries reduce low-grade inflammation in individuals with features of metabolic syndrome. Mol Nutr Food Res 2012;56:1501-10. doi:10.1002/ mnfr.201200195

95 Koopman KE, Caan MW, Nederveen AJ, et al. Hypercaloric diets with increased meal frequency, but not meal size, increase intrahepatic triglycerides: a randomized controlled trial. Hepatology 2014;60:545-53. doi:10.1002/hep. 27149

96 Lê KA, Faeh D, Stettler R, et al. A 4-wk high-fructose diet alters lipid metabolism without affecting insulin sensitivity or ectopic lipids in healthy humans. Am J Clin Nutr 2006;84:1374-9. doi:10.1093/ ajcn/84.6.1374

97 Lê KA, Ith M, Kreis R, et al. Fructose overconsumption causes dyslipidemia and ectopic lipid deposition in healthy subjects with and without a family history of type 2 diabetes. Am / Clin Nutr 2009:89:1760-5. doi:10.3945/ajcn.2008.27336

98 Lehtonen HM, Suomela JP, Tahvonen R, et al. Berry meals and risk factors associated with metabolic syndrome. Eur J Clin Nutr 2010;64:614-21. doi:10.1038/ejcn.2010.27

99 Lewis AS, McCourt HJ, Ennis CN, et al. Comparison of 5\% versus 15\% sucrose intakes as part of a eucaloric diet in overweight and obese subjects: effects on insulin sensitivity, glucose metabolism, vascular compliance, body composition and lipid profile. A randomised controlled trial. Metabolism 2013;62:694-702. doi:10.1016/j. metabol.2012.11.008

100 Liu G, Coulston A, Hollenbeck C, Reaven G. The effect of sucrose content in high and low carbohydrate diets on plasma glucose, 
insulin, and lipid responses in hypertriglyceridemic humans. J Clin Endocrinol Metab 1984:59:636-42. doi:10.1210/jcem-59-4-636

101 Lock S, Ford MA, Bagley R, Green LF. The effect on plasma lipids of the isoenergetic replacement of table sucrose by dried glucose syrup (maize-syrup solids) in the normal diet of adult men over a period of 1 year. Br J Nutr 1980;43:251-6. doi:10.1079/ BJN19800088

102 Lowndes J, Sinnett SS, Rippe JM. No Effect of Added Sugar Consumed at Median American Intake Level on Glucose Tolerance or Insulin Resistance. Nutrients 2015;7:8830-45. doi:10.3390/nu7105430

103 Madero M, Arriaga JC, Jalal D, et al. The effect of two energy-restricted diets, a low-fructose diet versus a moderate natural fructose diet, on weight loss and metabolic syndrome parameters: a randomized controlled trial. Metabolism 2011;60:1551-9. doi:10.1016/j. metabol.2011.04.001

104 Maersk M, Belza A, Stødkilde-Jørgensen H, et al. Sucrose-sweetened beverages increase fat storage in the liver, muscle, and visceral fat depot: a 6-mo randomized intervention study. Am J Clin Nutr 2012;95:283-9. doi:10.3945/ajcn.111.022533

105 Majid M, Younis MA, Naveed AK, Shah MU, Azeem Z, Tirmizi SH. Effects of natural honey on blood glucose and lipid profile in young healthy Pakistani males. J Ayub Med Coll Abbottabad 2013;25:44-7.

106 Maki KC, Nieman KM, Schild AL, et al. Sugar-sweetened product consumption alters glucose homeostasis compared with dairy product consumption in men and women at risk of type 2 diabetes mellitus. J Nutr 2015;145:459-66. doi:10.3945/ jn.114.204503

107 Malerbi DA, Paiva ES, Duarte AL, Wajchenberg BL. Metabolic effects of dietary sucrose and fructose in type II diabetic subjects. Diabetes Care 1996;19:1249-56. doi:10.2337/diacare.19.11.1249

108 Mark AB, Poulsen MW, Andersen S, et al. Consumption of a diet low in advanced glycation end products for 4 weeks improves insulin sensitivity in overweight women. Diabetes Care 2014;37:88-95 doi:10.2337/dc13-0842

109 Markey O, Le Jeune J, Lovegrove JA. Energy compensation following consumption of sugar-reduced products: a randomized controlled trial. Eur J Nutr 2016;55:2137-49.

110 McAteer EJ, O'Reilly G, Hadden DR. The effects of one month high fructose intake on plasma glucose and lipid levels in non-insulin-dependent diabetes. Diabet Med 1987;4:62-4 doi:10.1111/j.1464-5491.1987.tb00831.x

111 Mitsou EK, Kougia E, Nomikos T, Yannakoulia M, Mountzouris KC, Kyriacou A. Effect of banana consumption on faecal microbiota: a randomised, controlled trial. Anaerobe 2011;17:384-7. doi:10.1016/i.anaerobe.2011.03.018

112 Moazen S, Amani R, Homayouni Rad A, Shahbazian H, Ahmadi K, Taha Jalali M. Effects of freeze-dried strawberry supplementation on metabolic biomarkers of atherosclerosis in subjects with type 2 diabetes: a randomized double-blind controlled trial. Ann Nutr Metab 2013;63:256-64. doi:10.1159/000356053

113 Ngo Sock ET, Lê KA, Ith M, Kreis R, Boesch C, Tappy L. Effects of a short-term overfeeding with fructose or glucose in healthy young males. Br J Nutr 2010;103:939-43. doi:10.1017/ S0007114509992819

114 Njike VY, Faridi Z, Shuval K, et al. Effects of sugar-sweetened and sugar-free cocoa on endothelial function in overweight adults. Int Cardiol 2011;149:83-8. doi:10.1016/j.ijcard.2009.12.010

115 Osei K, Bossetti B. Dietary fructose as a natural sweetener in poorly controlled type 2 diabetes: a 12 -month crossover study of effects on glucose, lipoprotein and apolipoprotein metabolism. Diabet Med 1989;6:506-11. doi:10.1111/j.1464-5491.1989. tb01218.x

116 Osei K, Falko J, Bossetti BM, Holland GC. Metabolic effects of fructose as a natural sweetener in the physiologic meals of ambulatory obese patients with type II diabetes. Am / Med 1987;83:249-55. doi:10.1016/0002-9343(87)90693-0

117 Paganus A, Mäenpää J, Akerblom HK, Stenman UH, Knip M, Simell O. Beneficial effects of palatable guar and guar plus fructose diets in diabetic children. Acta Paediatr Scand 1987;76:76-81. doi:10.1111/j.1651-2227.1987.tb10418.x

118 Paineau DL, Beaufils F, Boulier A, et al. Family dietary coaching to improve nutritional intakes and body weight control: a randomized controlled trial. Arch Pediatr Adolesc Med 2008;162:34-43. doi:10.1001/archpediatrics.2007.2

119 Pelkonen R, Aro A, Nikkilä EA. Metabolic effects of dietary fructose in insulin dependent diabetes of adults. Acta Med Scand Suppl 1972;542:187-93.

120 Peterson DB, Lambert J, Gerring S, et al. Sucrose in the diet of diabetic patients--just another carbohydrate? Diabetologia 1986;29:216-20. doi:10.1007/BF00454878

121 Poppitt SD, Keogh GF, Prentice AM, et al. Long-term effects of ad libitum low-fat, high-carbohydrate diets on body weight and serum lipids in overweight subjects with metabolic syndrome. Am J Clin Nutr 2002;75:11-20. doi:10.1093/ajcn/75.1.11
122 Porta M, Pigino M, Minonne A, Morisio Guidetti L. Moderate amounts of sucrose with mixed meals do not impair metabolic control in patients with type II (non-insulin dependent) diabetes. Diabetes Nutr Metab 1989;2:133-7.

123 Puglisi MJ, Vaishnav U, Shrestha S, et al. Raisins and additional walking have distinct effects on plasma lipids and inflammatory cytokines. Lipids Health Dis 2008;7:14. doi:10.1186/1476-511X-7-14

124 Raben A, Astrup A. Leptin is influenced both by predisposition to obesity and diet composition. Int I Obes Relat Metab Disord 2000;24:450-9.

125 Raben A, Møller BK, Flint A, et al. Increased postprandial glycaemia, insulinemia, and lipidemia after 10 weeks' sucrose-rich diet compared to an artificially sweetened diet: a randomised controlled trial. Food Nutr Res 2011;55:55. doi:10.3402/fnr.v55i0.5961

126 Rath R, Masek J, Kujalová V, Slabochová Z. Effect of a high sugar intake on some metabolic and regulatory indicators in young men. Nahrung 1974;18:343-53. doi:10.1002/food.19740180402

127 Ravn-Haren G, Dragsted LO, Buch-Andersen T, et al. Intake of whole apples or clear apple juice has contrasting effects on plasma lipids in healthy volunteers. Eur J Nutr 2013;52:1875-89. doi:10.1007/s00394-012-0489-z

128 Reiser S, Hallfrisch J, Fields M, et al. Effects of sugars on indices of glucose tolerance in humans. Am / Clin Nutr 1986;43:151-9. doi:10.1093/ajcn/43.1.151

129 Reiser S, Powell AS, Scholfield DJ, Panda P, Fields M, Canary JJ. Day-long glucose, insulin, and fructose responses of hyperinsulinemic and nonhyperinsulinemic men adapted to diets containing either fructose or high-amylose cornstarch. Am J Clin Nutr 1989:50:1008-14. doi:10.1093/ajcn/50.5.1008

130 Ribeiro C, Dourado G, Cesar T. Orange juice allied to a reducedcalorie diet results in weight loss and ameliorates obesity-related biomarkers: A randomized controlled trial. Nutrition 2017;38:13-9. doi:10.1016/j.nut.2016.12.020

131 Rodríguez MC, Parra MD, Marques-Lopes I, De Morentin BE, González A, Martínez JA. Effects of two energy-restricted diets containing different fruit amounts on body weight loss and macronutrient oxidation. Plant Foods Hum Nutr 2005;60:219-24. doi:10.1007/s11130-005-8622-2

132 Santacroce G, Forlani G, Giangiulio S, Galuppi V, Pagani M, Vannini P. Long-term effects of eating sucrose on metabolic contro of type 1 (insulin-dependent) diabetic outpatients. Acta Diabetol Lat 1990;27:365-70. doi:10.1007/BF02580942

133 Saris WH, Astrup A, Prentice AM, et al. Randomized controlled trial of changes in dietary carbohydrate/fat ratio and simple vs complex carbohydrates on body weight and blood lipids: the CARMEN study. The Carbohydrate Ratio Management in European National diets. Int J Obes Relat Metab Disord 2000;24:1310-8.

134 Schwarz JM, Noworolski SM, Wen MJ, et al. Effect of a High-Fructose Weight-Maintaining Diet on Lipogenesis and Liver Fat. / Clin Endocrinol Metab 2015;100:2434-42. doi:10.1210/jc.2014-3678

135 Schwingshandl J, Rippel S, Unterluggauer M, Borkenstein M. Effect of the introduction of dietary sucrose on metabolic control in children and adolescents with type I diabetes. Acta Diabetol 1994;31:205-9. doi:10.1007/BF00571952

136 Silbernagel G, Machann J, Unmuth S, et al. Effects of 4-week veryhigh-fructose/glucose diets on insulin sensitivity, visceral fat and intrahepatic lipids: an exploratory trial. Br J Nutr 2011;106:79-86. doi:10.1017/S000711451000574X

137 Singh RB, Rastogi SS, Singh R, Niaz MA, Singh NK, Madhu SV. Effects on plasma ascorbic acid and coronary risk factors of adding guava fruit to the usual diet in hypertensives with mild to moderate hypercholesterolaemia. J Nutr Environ Med 1997;7:5-14. doi:10.1080/13590849762754

138 Sobrecases H, Lê KA, Bortolotti M, et al. Effects of short-term overfeeding with fructose, fat and fructose plus fat on plasma and hepatic lipids in healthy men. Diabetes Metab 2010;36:244-6. doi:10.1016/j.diabet.2010.03.003

139 Souto DL, Zajdenverg L, Rodacki M, Rosado EL. Does sucrose intake affect antropometric variables, glycemia, lipemia and C-reactive protein in subjects with type 1 diabetes?: a controlled-trial. Diabetol Metab Syndr 2013;5:67. doi:10.1186/1758-5996-5-67

140 Stanhope KL, Griffen SC, Bremer AA, et al. Metabolic responses to prolonged consumption of glucose- and fructose-sweetened beverages are not associated with postprandial or 24-h glucose and insulin excursions. Am J Clin Nutr 2011;94:112-9. doi:10.3945/ ajcn.110.002246

141 Stanhope KL, Bremer AA, Medici V, et al. Consumption of fructose and high fructose corn syrup increase postprandial triglycerides, LDL cholesterol, and apolipoprotein-B in young men and women. J Clin Endocrinol Metab 2011;96:E1596-605. doi:10.1210/jc.2011-1251

142 Sunehag AL, Toffolo G, Campioni M, Bier DM, Haymond MW. Short-term high dietary fructose intake had no effects on insulin sensitivity and secretion or glucose and lipid metabolism in healthy, obese adolescents. J Pediatr Endocrinol Metab 2008;21:225-35. doi:10.1515/JPEM.2008.21.3.225 
143 Sunehag AL, Toffolo G, Treuth MS, et al. Effects of dietary macronutrient content on glucose metabolism in children. J Clin Endocrinol Metab 2002;87:5168-78. doi:10.1210/jc.2002-020674

144 Surwit RS, Feinglos MN, McCaskill CC, et al. Metabolic and behavioral effects of a high-sucrose diet during weight loss. Am J Clin Nutr 1997:65:908-15. doi:10.1093/ajcn/65.4.908

145 Swanson JE, Laine DC, Thomas W, Bantle JP. Metabolic effects of dietary fructose in healthy subjects. Am J Clin Nutr 1992;55:851-6. doi:10.1093/ajcn/55.4.851

146 Swarbrick MM, Stanhope KL, Elliott SS, et al. Consumption of fructose-sweetened beverages for 10 weeks increases postprandial triacylglycerol and apolipoprotein-B concentrations in overweight and obese women. Br / Nutr 2008;100:947-52. doi:10.1017/ S0007114508968252

147 Szanto S, Yudkin J. The effect of dietary sucrose on blood lipids, serum insulin, platelet adhesiveness and body weight in human volunteers. Postgrad Med / 1969;45:602-7. doi:10.1136/ pgmj.45.527.602

148 Tate DF, Turner-McGrievy G, Lyons E, et al. Replacing caloric beverages with water or diet beverages for weight loss in adults: main results of the Choose Healthy Options Consciously Everyday (CHOICE) randomized clinical trial. Am J Clin Nutr 2012;95:555-63. doi:10.3945/ajcn.111.026278

149 Vaisman N, Niv E, Izkhakov Y. Catalytic amounts of fructose may improve glucose tolerance in subjects with uncontrolled non-insulin-dependent diabetes. Clin Nutr 2006;25:617-21. doi:10.1016/j.clnu.2005.11.013

150 van Meijl LE, Mensink RP. Low-fat dairy consumption reduces systolic blood pressure, but does not improve other metabolic risk parameters in overweight and obese subjects. Nutr Metab Cardiovasc Dis 2011;21:355-61. doi:10.1016/j.numecd.2009.10.008

151 Volp AC, Hermsdorff HH, Bressan J. Glycemia and insulinemia evaluation after high-sucrose and high-fat diets in lean and overweight/obese women. J Physiol Biochem 2008;64:103-13. doi:10.1007/BF03168238

152 Volp AC, Hermsdorff HM, Bressan ]. [Effect of high sucrose- and highfat diets ingested under free-living conditions in insulin resistance in normal weight and overweight women]. Nutr Hosp 2007;22:46-60.

$153 \mathrm{Lin} \mathrm{L,} \mathrm{Chu} \mathrm{H,} \mathrm{Hodges} \mathrm{IS.} \mathrm{Alternative} \mathrm{measures} \mathrm{of} \mathrm{between-study}$ heterogeneity in meta-analysis: Reducing the impact of outlying studies. Biometrics 2017;73:156-66. doi:10.1111/biom.12543

154 Livesey G, Taylor R. Fructose consumption and consequences for glycation, plasma triacylglycerol, and body weight: meta-analyses and meta-regression models of intervention studies. Am J Clin Nutr 2008;88:1419-37.

155 Sievenpiper JL. Sickeningly sweet: does sugar cause chronic disease? No. Can J Diabetes 2016;40:287-95. doi:10.1016/j. jcjd.2016.05.006

156 Tsilas CS, de Souza RJ, Mejia SB, et al. Relation of total sugars, fructose and sucrose with incident type 2 diabetes: a systematic review and meta-analysis of prospective cohort studies. CMAJ 2017;189:E711-20.

157 Atkinson FS, Foster-Powell K, Brand-Miller JC. International tables of glycemic index and glycemic load values: 2008. Diabetes Care 2008;31:2281-3. doi:10.2337/dc08-1239

158 Livesey G, Taylor R, Hulshof T, Howlett J. Glycemic response and health--a systematic review and meta-analysis: relations between dietary glycemic properties and health outcomes. Am J Clin Nutr 2008;87:258S-68S. doi:10.1093/ajcn/87.1.258S

159 Brand-Miller JC, Petocz P, Colagiuri S. Meta-analysis of low-glycemic index diets in the management of diabetes: response to Franz. Diabetes Care 2003;26:3363-4, author reply 3364-5. doi:10.2337/diacare 26.12.3363

160 Jenkins DJ, Wolever TM, Collier GR, et al. Metabolic effects of a low-glycemic-index diet. Am J Clin Nutr 1987;46:968-75. doi:10.1093/ajcn/46.6.968

161 Ford ES, Liu S. Glycemic index and serum high-density lipoprotein cholesterol concentration among us adults. Arch Intern Med 2001;161:572-6. doi:10.1001/archinte.161.4.572

162 Liu S, Manson JE, Stampfer MJ, et al. Dietary glycemic load assessed by food-frequency questionnaire in relation to plasma high-density-lipoprotein cholesterol and fasting plasma triacylglycerols in postmenopausal women. Am / Clin Nutr 2001;73:560-6. doi:10.1093/ajcn/73.3.560

163 Lattimer JM, Haub MD. Effects of dietary fiber and its components on metabolic health. Nutrients 2010;2:1266-89. doi:10.3390/nu2121266
164 Jenkins DJ, Srichaikul K, Kendall CW, et al. The relation of low glycaemic index fruit consumption to glycaemic control and risk factors for coronary heart disease in type 2 diabetes. Diabetologia 2011;54:271-9. doi:10.1007/s00125-010-1927-1

165 Hawkins M, Gabriely I, Wozniak R, Vilcu C, Shamoon H, Rossetti L. Fructose improves the ability of hyperglycemia per se to regulate glucose production in type 2 diabetes. Diabetes 2002;51:606-14 doi:10.2337/diabetes.51.3.606

166 Petersen KF, Laurent D, Yu C, Cline GW, Shulman GI. Stimulating effects of low-dose fructose on insulin-stimulated hepatic glycogen synthesis in humans. Diabetes 2001;50:1263-8. doi:10.2337/ diabetes.50.6.1263

167 Braunstein CR, Noronha JC, Glenn AJ, et al. A double-blind, randomized controlled, acute feeding equivalence trial of small, catalytic doses of fructose and allulose on postprandial blood glucose metabolism in healthy participants: the Fructose and Allulose Catalytic Effects (FACE) Trial. Nutrients 2018;10:E750. doi:10.3390/ nu10060750

168 Noronha JC, Braunstein CR, Glenn AJ, et al. The effect of small doses of fructose and allulose on postprandial glucose metabolism in type 2 diabetes: A double-blind, randomized, controlled, acute feeding, equivalence trial. Diabetes Obes Metab 2018;20:2361-70. doi:10.1111/dom.1337

169 Lan-Pidhainy X, Wolever TM. The hypoglycemic effect of fat and protein is not attenuated by insulin resistance. Am / Clin Nutr 2010;91:98-105. doi:10.3945/ajcn.2009.28125

170 Wolever TM, van Klinken BJ, Bordenave N, et al. Reformulating cereal bars: high resistant starch reduces in vitro digestibility but not in vivo glucose or insulin response; whey protein reduces glucose but disproportionately increases insulin. Am J Clin Nutr 2016;104:995-1003. doi:10.3945/ajcn.116.132431

171 Jakubowicz D, Froy O, Ahrén B, et al. Incretin, insulinotropic and glucose-lowering effects of whey protein pre-load in type 2 diabetes: a randomised clinical trial. Diabetologia 2014;57:1807-11. doi:10.1007/s00125-014-3305-x

172 Mozaffarian D. Dietary and policy priorities for cardiovascular disease, diabetes, and obesity: a comprehensive review. Circulation 2016;133:187-225. doi:10.1161/ CIRCULATIONAHA.115.018585

173 Sievenpiper JL, de Souza RJ, Mirrahimi A, et al. Effect of fructose on body weight in controlled feeding trials: a systematic review and meta-analysis. Ann Intern Med 2012;156:291-304. doi:10.7326/0003-4819-156-4-201202210-00007

174 Silbernagel G, Kovarova M, Cegan A, et al. High hepatic SCD1 activity is associated with low liver fat content in healthy subjects under a lipogenic diet. J Clin Endocrinol Metab 2012;97:E2288-92. doi:10.1210/jc.2012-2152

175 Wang DD, Sievenpiper JL, de Souza RJ, et al. The effects of fructose intake on serum uric acid vary among controlled dietary trials. J Nutr 2012;142:916-23. doi:10.3945/in.111.151951

176 Chiu S, Sievenpiper JL, de Souza RJ, et al. Effect of fructose on markers of non-alcoholic fatty liver disease (NAFLD): a systematic review and meta-analysis of controlled feeding trials. Eur / Clin Nutr 2014;68:416-23. doi:10.1038/ejcn.2014.8

177 David Wang D, Sievenpiper JL, de Souza RJ, et al. Effect of fructose on postprandial triglycerides: a systematic review and meta-analysis of controlled feeding trials. Atherosclerosis 2014;232:125-33. doi:10.1016/j.atherosclerosis.2013.10.019

178 van Buul V], Tappy L, Brouns Fl. Misconceptions about fructose-containing sugars and their role in the obesity epidemic. Nutr Res Rev 2014;27:119-30. doi:10.1017/ S0954422414000067

179 Mozaffarian D, Hao T, Rimm EB, Willett WC, Hu FB. Changes in diet and lifestyle and long-term weight gain in women and men. N Engl J Med 2011;364:2392-404. doi:10.1056/NEJMoa1014296

180 Kaiser KA, Shikany JM, Keating KD, Allison DB. Will reducing sugar-sweetened beverage consumption reduce obesity? Evidence supporting conjecture is strong, but evidence when testing effect is weak. Obes Rev 2013;14:620-33. doi:10.1111/obr.12048

181 Te Morenga L, Mallard S, Mann J. Dietary sugars and body weight: systematic review and meta-analyses of randomised controlled trials and cohort studies. BMJ 2012;346:e7492. doi:10.1136/bmj. e7492

Web appendix: Supplementary tables and figures 